\title{
The Emissivity of Foam-Covered Water Surface at L-Band: Theoretical Modeling and Experimental Results From the Frog 2003 Field Experiment
}

\author{
Adriano Camps, Senior Member, IEEE, Mercè Vall-llossera, Member, IEEE, Ramón Villarino, Student Member, IEEE, \\ Nicolas Reul, Bertrand Chapron, Ignasi Corbella, Member, IEEE, Núria Duffo, Member, IEEE, \\ Francesc Torres, Member, IEEE, Jorge José Miranda, Student Member, IEEE, Roberto Sabia, Student Member, IEEE, \\ Alessandra Monerris, Student Member, IEEE, and Rubén Rodríguez
}

\begin{abstract}
Sea surface salinity can be measured by microwave radiometry at $\mathrm{L}$-band (1400-1427 $\mathrm{MHz})$. This frequency is a compromise between sensitivity to the salinity, small atmospheric perturbation, and reasonable pixel resolution. The description of the ocean emission depends on two main factors: 1) the sea water permittivity, which is a function of salinity, temperature, and frequency, and 2) the sea surface state, which depends on the wind-induced wave spectrum, swell, and rain-induced roughness spectrum, and by the foam coverage and its emissivity. This study presents a simplified two-layer emission model for foam-covered water and the results of a controlled experiment to measure the foam emissivity as a function of salinity, foam thickness, incidence angle, and polarization. Experimental results are presented, and then compared to the two-layer foam emission model with the measured foam parameters used as input model parameters. At 37 psu salt water the foam-induced emissivity increase is $\sim 0.007$ per millimeter of foam thickness (extrapolated to nadir), increasing with increasing incidence angles at vertical polarization, and decreasing with increasing incidence angles at horizontal polarization.
\end{abstract}

Index Terms-Brightness temperature, emission, foam, microwave radiometry, salinity, sea.

\section{INTRODUCTION}

$\mathbf{T}$ HE IMPROVEMENT of weather prediction, e.g., for natural catastrophes, requires the knowledge of soil moisture (SM) and sea surface salinity (SSS) on a global scale. The knowledge of the SSS distribution at a global scale with a moderate revisit time is important to climate predictions, since SSS is a tracer of sea surface currents and an indicator of the difference between evaporation and precipitation (E-P). Water density is determined by temperature and salinity, and hence the

Manuscript received July 8, 2004; revised October 9, 2004. The foam emission modeling study was sponsored by the European Space Agency under Contract 5165/01/NL/SF. The FROG 2003 campaign was sponsored in part by MCyT A.E. ESP2001-4524-PE, in part by the Spanish Comisión Interministerial de Ciencia y Tecnología and EU FEDER (CICYT TIC2002-04451-C02-01), and in part by Grant "Distinció de Recerca de la Generalitat de Catalunya," resolution: UNI/2120/2002 on July 19, DOGC $3684,24 / 07 / 2002$.

A. Camps, M. Vall-llossera, R. Villarino, I. Corbella, N. Duffo, F. Torres, J. J. Miranda, R. Sabia, A. Monerris, and R. Rodriguez are with the Department of Signal Theory and Communications, Universitat Politècnica de Catalunya, E-08034 Barcelona, Spain (e-mail: camps@tsc.upc.es).

N. Reul and B. Chapron are with the IFREMER, Deparement d'Océanographie Physique et Spatiale, Laboratoire d'Océanographie Spatiale, 29280 Plouzané, France.

Digital Object Identifier 10.1109/TGRS.2004.839651 thermo-haline circulation can also be monitored by SSS measurements. Salinity monitoring is useful to improve the quality of the El Niño Southern Oscillation (ENSO) numerical model predictions, as well [1], [2].

At present, there are two planned space missions to measure global sea surface salinity maps with 10-30-day revisit time: the Soil Moisture and Ocean Salinity (SMOS) Earth Explorer Opportunity mission from the European Space Agency (ESA), and the Aquarius Earth System Science Pathfinder (ESSP) mission from the National Aeronautics and Space Administration (NASA), with launch dates in February 2007 and September 2008, respectively.

The SSS retrieval from microwave radiometric measurements is based on the fact that the dielectric constant of seawater is a function of salinity and temperature [3]. The sensitivity of brightness temperature $\left(T_{B}\right)$ to SSS is maximum at low microwave frequencies, and the optimum conditions for salinity retrieval are found at L-band, where there is a protected band for passive observations (1400-1427 MHz). However, even at this frequency the sensitivity of $T_{B}$ to SSS is low: $0.5 \mathrm{~K}$ per psu for a sea surface temperature (SST) of $20^{\circ} \mathrm{C}$, decreasing to $0.25 \mathrm{~K}$ per psu for an SST of $0{ }^{\circ} \mathrm{C}$. Since other variables influence the $T_{B}$ signal (polarization, incidence angle, sea surface temperature, roughness and foam), unless they are properly accounted for, the SSS determination will be erroneous.

During SMOS Phase A two field experiments named the Wind and Salinity Experiment (WISE) were sponsored by the ESA in the fall of 2000 and 2001 to better understand the wind and sea state effects on the L-band brightness temperatures. They consisted of acquiring long time series of $T_{B}$ from an oil rig in the northern Mediterranean Sea to relate it to the sea surface roughness (wind speed, significant wave height) and the instantaneous foam coverage [4].

Several effects were not completely understood during the WISE field experiments: the emissivity of foam and the impact of rain and oil slicks on the $T_{B}$ variations. Under Spanish National funds, the Foam, Fain, Oil Slicks and GPS Reflectometry (FROG) field experiment was carried out at the Institut de Recerca i Tecnologia Agroalimentàries (IRTA) facilities at the Ebro River delta.

This work is organized into two well-defined parts. In the first one, a two-layer sea foam emission model at L-band is 


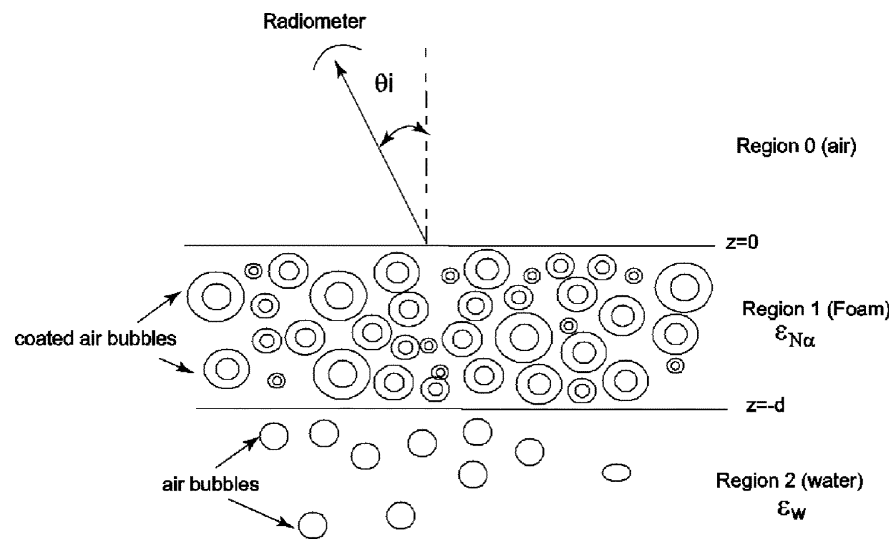

Fig. 1. Geometrical configuration for thermal emission from foam-covered ocean. The foam layer is region 1 and is absorptive and scattering. Region 2 is air bubbles embedded in sea water and is absorptive (from [5]; see Fig. 3).

presented. In the second one, the FROG 2003 field experiment is described, and the foam emissivity measurements at vertical and horizontal polarizations are presented in a wide range of water salinities from $0-37 \mathrm{psu}$. These measurements are then compared to the model presented in the first part using the measured foam parameters: bubble radii histograms, bubbles' water coating thickness, derived bubbles' packing coefficient, foam layer thickness, and the void fraction beneath the foam layer.

\section{SeA FoAm Emissivity Modeling AT L-BAND}

Foam and whitecaps belong to the class of colloidal systems that include two phases: atmospheric gases and sea water. In the present work, the foam layers at the ocean surface are modeled as a medium of densely packed sticky spherical air bubbles, coated with thin seawater coating, following the approach of Guo et al. [5]. The dipole approximation model developed by Dombrovskiy and Raizer [6] is then used to describe the effective permittivity of the system.

\section{A. Brightness Temperature Modeling of the Foam-Water System}

Following Guo et al. [5], it is assumed that foam on the ocean surface is composed of nearly spherical coated bubbles described by an outer radius $r$, made of an air core with permittivity $\varepsilon_{a}$, surrounded by a shell of sea water with thickness $\delta$ and permittivity $\varepsilon_{\mathrm{w}}$. The foam-covered ocean is modeled by the succession of three media: the air (region 0 ), a foam layer defined as a region of effective permittivity $\varepsilon_{N \alpha}$ with a layer thickness $d$ (region 1), and the underlying seawater with some air bubbles (region 2) with permittivity $\varepsilon_{\mathrm{w}}$ (see Fig. 1). Boundaries between each region are assumed flat.

The brightness temperature of the foam-water system at incidence angle $\theta_{i}$ and polarization $p=\mathrm{h}$ (horizontal) or v (vertical) is then equal to

$$
T_{B p}\left(\theta_{i}\right)=T_{s}\left[1-\left|R_{p}\left(\theta_{i}\right)\right|^{2}\right]
$$

where $T_{s}$ is the foam layer physical temperature, the coefficient $R_{p}$ is the reflection coefficient of the foam layer medium with the effective dielectric constant $\varepsilon_{N \alpha}$ and is given by

$$
R_{p}\left(\theta_{i}\right)=\frac{R_{p}^{01}\left(\theta_{i}\right) e^{-j 2 \psi}+R_{p}^{12}\left(\theta_{i}\right)}{e^{-j 2 \psi}+R_{p}^{01}\left(\theta_{i}\right) R_{p}^{12}\left(\theta_{i}\right)}
$$

where $\Psi$ is an attenuation factor that depends on the foam layer thickness $d$, the electromagneticwavelength $\lambda_{0}$, and the effective permittivity $\varepsilon_{N \alpha}$

$$
\psi=\frac{2 \pi d}{\lambda_{0}} \sqrt{\varepsilon_{N \alpha}-\sin ^{2} \theta_{i}} .
$$

In (2), $R_{p}^{01}$ are the Fresnel reflection coefficients between the air (region 0 ) and the foam (region 1)

$$
\begin{aligned}
R_{\mathrm{h}}^{01}\left(\theta_{i}\right) & =\frac{\cos \left(\theta_{i}\right)-\sqrt{\varepsilon_{N \alpha}-\sin ^{2} \theta_{i}}}{\cos \left(\theta_{i}\right)+\sqrt{\varepsilon_{N \alpha}-\sin ^{2} \theta_{i}}} \\
R_{\mathrm{v}}^{01}\left(\theta_{i}\right) & =\frac{\varepsilon_{N \alpha} \cos \left(\theta_{i}\right)-\sqrt{\varepsilon_{N \alpha}-\sin ^{2} \theta_{i}}}{\varepsilon_{N \alpha} \cos \left(\theta_{i}\right)+\sqrt{\varepsilon_{N \alpha}-\sin ^{2} \theta_{i}}}
\end{aligned}
$$

and $R_{p}^{12}$ are the Fresnel reflection coefficients between foam (region 1) and water (region 2)

$$
\begin{aligned}
R_{\mathrm{h}}^{12}\left(\theta_{i}\right) & =\frac{\sqrt{\varepsilon_{N \alpha}-\sin ^{2}\left(\theta_{i}\right)}-\sqrt{\varepsilon_{\mathrm{w}}-\sin ^{2} \theta_{i}}}{\sqrt{\varepsilon_{N \alpha}-\sin ^{2}\left(\theta_{i}\right)}+\sqrt{\varepsilon_{\mathrm{w}}-\sin ^{2} \theta_{i}}} \\
R_{\mathrm{h}}^{12}\left(\theta_{i}\right) & =\frac{\varepsilon_{\mathrm{w}} \sqrt{\varepsilon_{N \alpha}-\sin ^{2}\left(\theta_{i}\right)}-\varepsilon_{N \alpha} \sqrt{\varepsilon_{\mathrm{w}}-\sin ^{2} \theta_{i}}}{\varepsilon_{\mathrm{w}} \sqrt{\varepsilon_{N \alpha}-\sin ^{2}\left(\theta_{i}\right)}+\varepsilon_{N \alpha} \sqrt{\varepsilon_{\mathrm{w}}-\sin ^{2} \theta_{i}}} .
\end{aligned}
$$

Region 2 consists of air bubbles embedded in the ocean background and is assumed to be absorptive. To solve (1)-(5), one needs to define an effective permittivity for region 1, namely $\varepsilon_{N \alpha}$, and for region 2 , namely $\varepsilon_{\mathrm{w}}$.

\section{B. Effective Permittivity of Sea Foam Formations at L-Band}

The main parameter of the previous multilayer emissivity model for foam is the effective permittivity $\varepsilon_{N \alpha}$ of the foam layer considered. To define this parameter, the well-known Lorenz-Lorentz and van de Hulst equations can be used and modified for the polydispersed system of bubbles. The first formula takes into account dipole interaction of bubbles in a close-packed dispersed system (the quasi-static approximation). The van de Hulst equations describe the contribution of the multipole moment of bubbles into the effective permittivity of the system. Spectral calculations by Cherny and Raizer [7] show that the first resonant electromagnetic effects by van de Hulst's mechanism occur for bubbles' radius $a \approx \lambda_{0} / 4$. At L-band $\left(\lambda_{0}=21 \mathrm{~cm}\right)$; this corresponds to bubble diameters on the order of $10 \mathrm{~cm}$. Such very large bubbles are extremely rare at the sea surface and therefore, the multipole mechanism may be neglected at L-band for which only the dipole term 
may be considered. In the present work, we use the dipole approximation model developed by Dombrovskiy and Raizer [6] to describe the effective permittivity of the system. It involves the use of a modification of the Lorenz-Lorentz equation and yields the following simple formula for the complex effective permittivity $\varepsilon_{N \alpha}$ of a foam layer [6], [7]:

$$
\varepsilon_{N \alpha}=\frac{1+\frac{8}{3} \pi \overline{N \cdot \alpha(r)}}{1-\frac{4}{3} \pi \overline{N \cdot \alpha(r)}}
$$

where

$$
\overline{N \cdot \alpha(r)}=\frac{\kappa \int \alpha(r) p_{f}(r) d r}{\frac{4}{3} \int r^{3} p_{f}(r) d r}
$$

and $N$ is the volumetric concentration of the bubbles, $\alpha(r)$ is the complex polarizability of a single bubble with external radius $r$, $\kappa$ is the so-called packing coefficient or stickiness parameter, and $p_{f}(r)$ is the normalized probability distribution function of the bubbles' size. In natural media such as foam, the densely packed particles can have adhesive forces that make them adhere to form aggregates. This effect is accounted for in the model by the stickiness parameter $\kappa$, which is inversely proportional to the strength of the attractive forces between bubbles [8].

According to Dombrovskiy and Raizer [6], the complex polarizability depends on the external radius of the bubbles $r$, the complex permittivity of the shell medium (salt water) $\varepsilon_{\mathrm{w}}$, and the bubbles' filling factor $q=1-\delta / r$ following

$$
\alpha(r)=r^{3} \frac{\left(\varepsilon_{\mathrm{w}}-1\right)\left(2 \varepsilon_{\mathrm{w}}+1\right)\left(1-q^{3}\right)}{\left(\varepsilon_{\mathrm{w}}+2\right)\left(2 \varepsilon_{\mathrm{w}}+1\right)\left(1-q^{3}\right)+9 \varepsilon_{\mathrm{w}} q^{3}} .
$$

Since the bubble size distribution depends on the vertical position within the foam layer, the effective permittivity depends on the vertical position as well: $\varepsilon_{N \alpha}=\varepsilon_{N \alpha}(z)$. In the simplest case, the foam-water system may be modeled as a succession of elementary foam layers, each of them having a homogeneous effective dielectric constant. However, the exact dependence of such function with vertical position, which depends on the vertical distribution of the bubbles' size, is very poorly known. It is very likely that the vertical distribution of the bubbles' size $p_{f}(r, z)$ is a function of the intensity and scale of the underlying breaking event. Moreover it will certainly strongly evolve during a transient breaking event. Nevertheless, in order to keep a tractable number of parameters in the present model, we choose to consider a uniform vertical distribution of bubbles' sizes $p_{f}(r, z)=p_{f}(r)$ within the foam layer.

The foam void fraction (i.e., the ratio of the volume of air to the total volume of the foam) depends on the distribution of the bubbles' filling factor $q$. Therefore, the distribution of bubbles radii $p_{f}(r)$ together with the distribution of coating thicknesses $f(\delta)$ determine the foam layer void fraction. In the present simplified model, we fixed the value of the shell thickness $\delta$, but the outer bubble radius $r$ is a random variable. According to Dombrovskiy [9], this approximation reflects an experimentally established fact for an emulsion layer of foam (young foam), but it requires verification for a foam with honeycomb structure

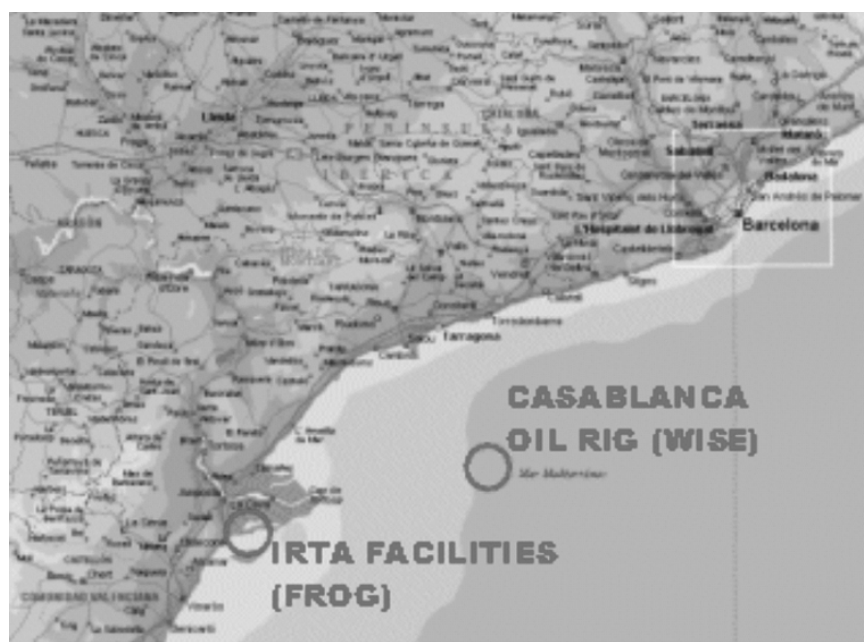

Fig. 2. Location of the WISE and FROG field experiments.

(aged foam). Numerous observations of oceanic bubble size distributions are reported in the literature based on acoustic, photographic, optical, and holographic methods [11]. Currently, it is not clear how to parameterize the ocean surface bubble size distribution. Following Bordonskiy et al. [12] and Dombrovskskiy and Raizer [6], we used a $\gamma$ distribution for the size distribution function of the bubbles

$$
p_{f}(r)=\frac{A^{B+1}}{\Gamma(B+1)} r^{B} e^{-A r}
$$

where $A$ and $B$ are parameters of the distribution with $r_{p}=$ $A / B$ being the most probable radius.

Finally, to calculate $\varepsilon_{\mathrm{w}}$, a simple physical model based on induced dipoles is used. Let $\varepsilon_{\mathrm{sw}}$ denote the permittivity of the seawater (see [13] for $\varepsilon_{\mathrm{sw}}$ at L-band), and $f_{a}$ the fractional volume occupied by the air bubbles. Then, the effective permittivity $\varepsilon_{\mathrm{w}}$ is given by the Maxwell-Garnett mixing formula [5]

$$
\varepsilon_{\mathrm{w}}=\varepsilon_{\mathrm{sw}} \frac{1+2 f_{a} y}{1-f_{a} y}
$$

where

$$
y=\frac{1-\varepsilon_{\mathrm{sw}}}{1+2 \varepsilon_{\mathrm{sw}}} .
$$

Note that the effective permittivity $\varepsilon_{\mathrm{w}}$ here does not include scattering extinction, which is small due to the fact that the seawater is heavily absorptive. According to our simplified emissivity model for foam, the brightness temperature induced by a sea foam layer is a function of

$$
T_{B}=\text { function }\left(\theta_{i}, f, p, T_{s}, r_{p}, \delta, \kappa, d, f_{a}, \mathrm{SSS}, \mathrm{SST}\right)
$$

where $\theta_{i}$ is the radiometer incidence angle, $f$ the electromagnetic frequency, $p$ is the polarization, $T_{s}$ is the foam physical temperature, $r_{p}$ is the most probable radius, $\delta$ is the bubbles' water coating thickness, $\kappa$ is the bubbles' packing coefficient (same as stickiness parameter), $d$ is the foam layer thickness, $f_{a}$ is the void fraction beneath the foam layer, and finally, SSS 


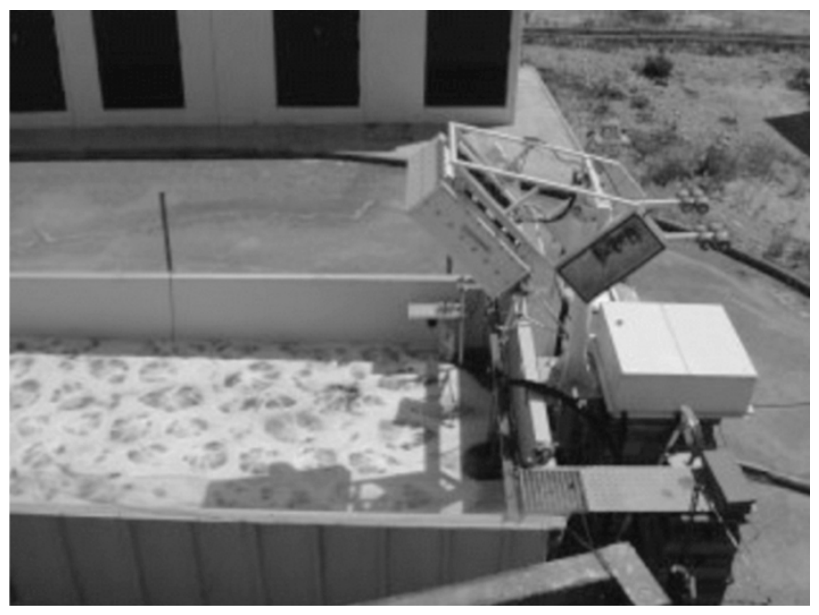

(a)

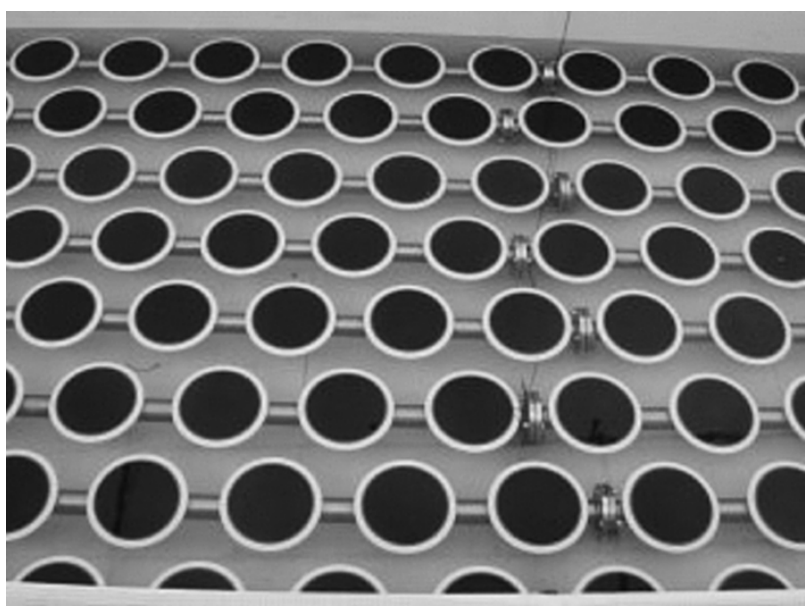

(b)

Fig. 3. (a) Pool filled with water during a foam emissivity measurement incidence angle scan. (b) Detail of the air diffusers used to generate foam.

and SST are the sea surface salinity and temperature, respectively. All these parameters are either known $\left(\theta_{i}, f, p\right)$ or measured $\left(T_{s}, r_{p}, \delta, d, f_{a}, \mathrm{SST}, \mathrm{SSS}\right)$, except the packing coefficient $(\kappa)$ that will be derived by minimizing the rms error between the FROG 2003 measurements and the theoretical model (see Section III-B).

\section{SEA FOAM EMISSIVITY MEASUREMENTS AT L-BAND}

\section{A. FROG 2003 Field Experiment Description}

The FROG 2003 experiment was sponsored by the Spanish Government to determine the emission of these factors. The controlled experiment was performed at the facilities of the Institut de Recerca en Tècniques Agropecuàries (IRTA) at Poble Nou del Delta, in the Ebro River mouth (Fig. 2).

The L-band Automatic Radiometer (LAURA) radiometer [4] was mounted on one side of a $3 \mathrm{~m} \times 7 \mathrm{~m}$ pool filled with a mixture of sea water and fresh water from the Ebro River. The river water was mixed with the sea water to adjust the salinity over the range from 0-37 psu [Fig. 3(a)]. A metallic net was mounted around the pool, and at the edges the net was inclined $45^{\circ}$ to reflect the sky radiation, avoiding contamination of the measurements from ground radiation collected through the secondary
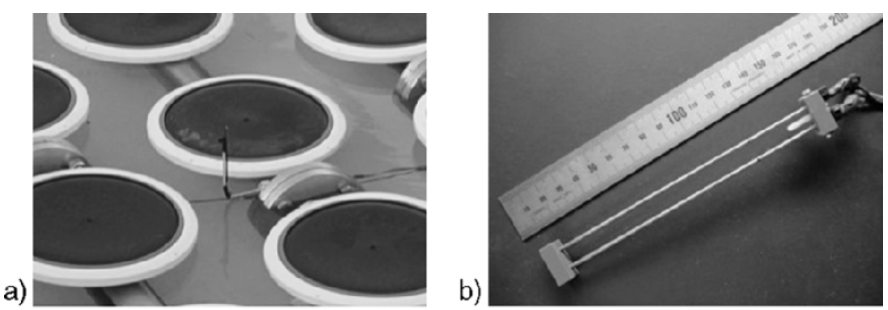

c)
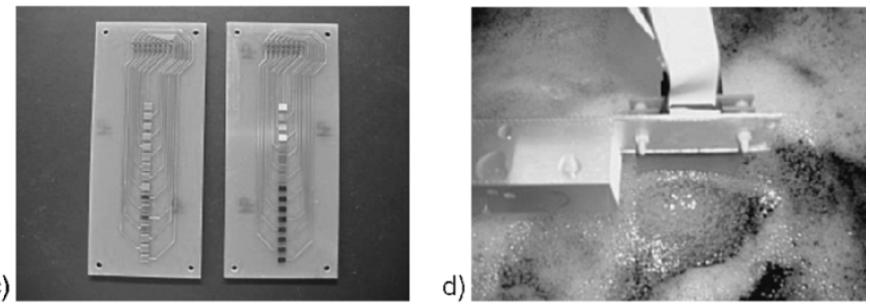

e)
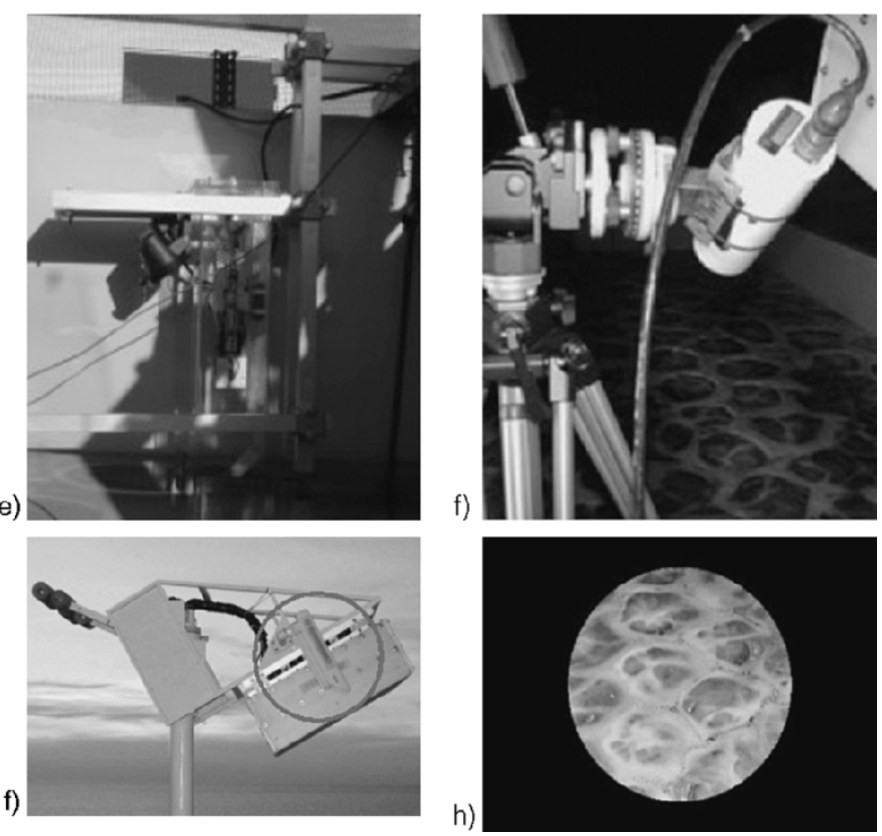

Fig. 4. Suite of instruments deployed to acquire ancillary data. (a) Six subsurface temperature sensors. (b) Metal bars of the instantaneous surface level sensor. (c) and (d) Array of 16 gold electrodes of the air fraction measurement system. (e) Periscope with video camera to acquire vertical foam profiles. (f) Infrared radiometer to measure surface emission with foam. (g) Video camera to derive surface foam coverage [as in (h)].

lobes of the antenna, and enlarging the radio-electric horizon. The measurement strategy consisted of performing incidence angle scans from $25^{\circ}$ to $55^{\circ}$, in $5^{\circ}$ steps, and measuring the surface's emissivity with the foam generators off, on, and finally off again at each incidence angle. All measurements were performed after sunset to avoid sun contamination, and the pool was oriented to the north which minimized the Galactic background noise. Foam was created by a network of 104 air diffusers placed at the bottom of the pool, and connected to an adjustable air pump with a maximum air flow of $500 \mathrm{~m}^{3} / \mathrm{h}$ [Fig. 3(b)].

A series of instruments was deployed to acquire ancillary data to be used as inputs to theoretical models as follows:

- six temperature sensors located below the water surface [Fig. 4(a)];

- two metallic bars used in a conductivity-based instantaneous surface level sensor [Fig. 4(b)]; 
a)

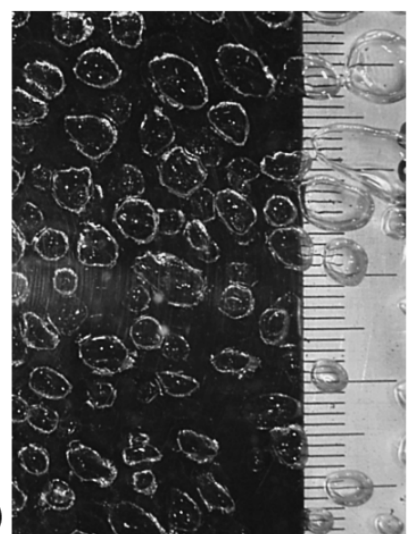

d)

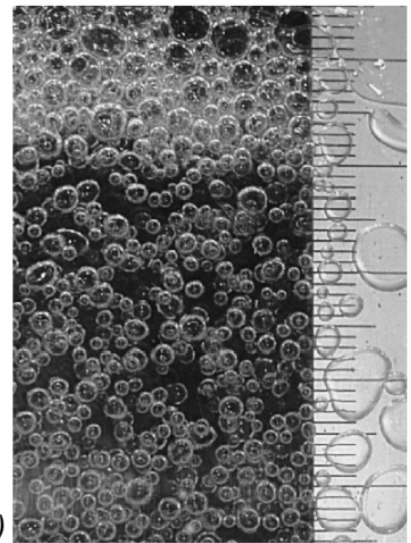

g)

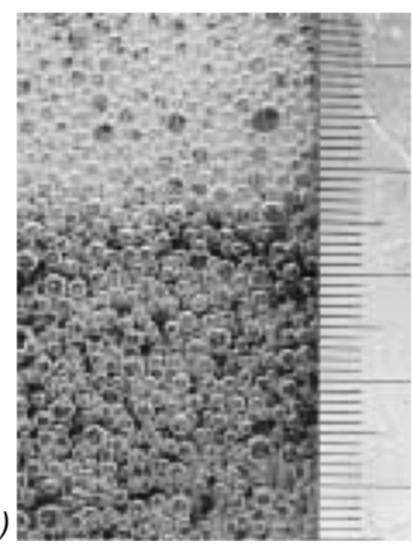

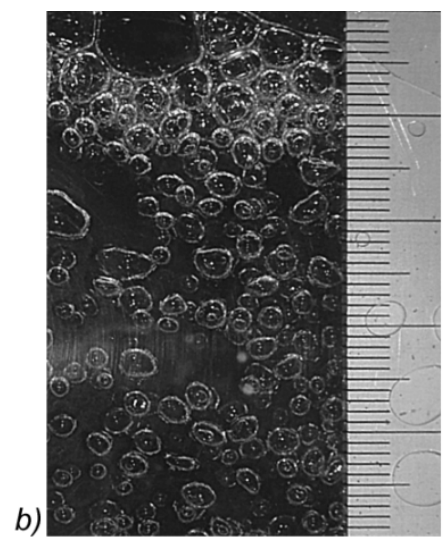
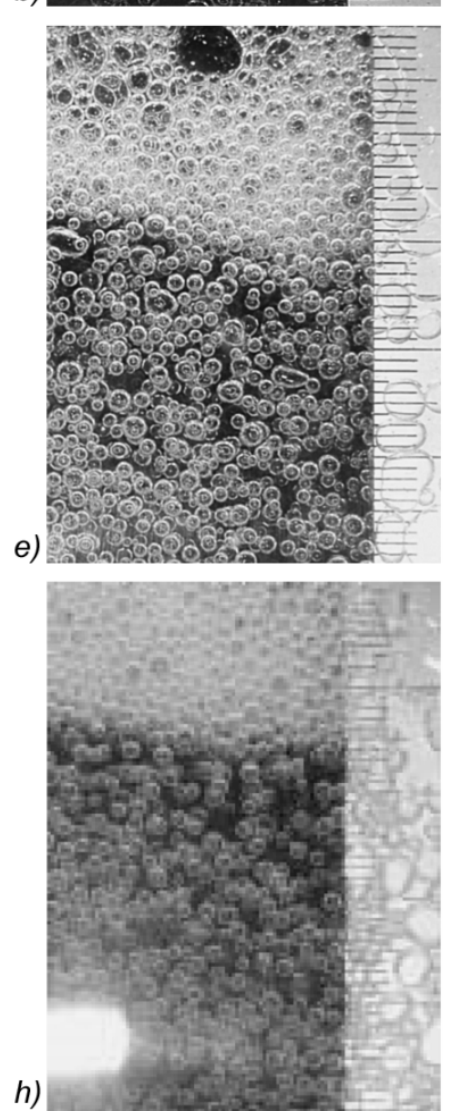

c)
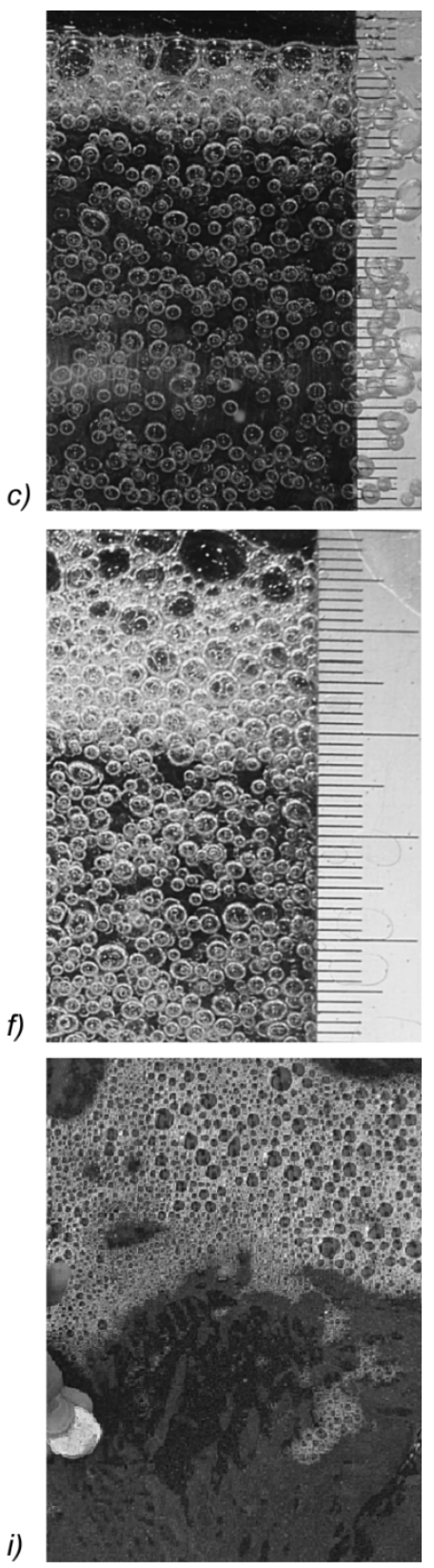

Fig. 5. Foam vertical profiles at different salinities (scale in centimeters). (a) 0 psu, (b) $5 \mathrm{psu}$, (c) $10 \mathrm{psu}$, (d) $15 \mathrm{psu}$, (e) $20 \mathrm{psu}$, (f) $25 \mathrm{psu}$, (g) $30 \mathrm{psu}$, (h) $37 \mathrm{psu}$, and (i) horizontal view of natural sea surface bubbles (photograph from Gran Canaria island, SSS33.8 psu, reference size $=0.50$ Euro coin).

- array of 16 gold electrodes [Fig. 4(c)] of a conductivitybased subsurface void fraction profiler [Fig. 4(d)];

- Ultrak video camera with a large angular lens mounted on a periscope to acquire foam vertical profiles [Fig. 4(e)];

- CIMEL CE 312 four-band thermal-infrared radiometer: 8-13, 11.5-12.5, 10.5-11.5, and 8.2-9.2 $\mu \mathrm{m}$ [Fig. 4(f)], from the Universitat de València;

- Sony SSC-DC393 video camera and zoom [Fig. 4(g)] to match the field of view to the radiometer's antenna beam [Fig. 4(h)], used to derive the water surface's foam coverage;

- portable meteorological station used to measure air temperature, pressure and relative humidity, and wind speed and direction.

\section{B. Radiometric Measurements}

Foam-Free Measurements: The first measurements consisted of measuring the emissivity of the flat water surface at different salinity levels

$$
e_{p}^{\text {Water }}(f, \theta, \mathrm{SSS}, \mathrm{SST})=1-\Gamma_{p}^{\text {Fresnel }}\left(\theta, \varepsilon_{r}(f, \mathrm{SSS}, \mathrm{SST})\right) \text {. }
$$

Down-welling radiation and finite beamwidth effects were corrected. As expected, the brightness temperatures (or alternatively emissivities) decrease with increasing salinity levels, in agreement with the theory using the Klein-Swift dielectric constant model [9].

${ }^{1}$ The goodness of the agreement between the modeled $T_{B}$ and the measured $T_{B}$ is $\sim 0.12 \mathrm{~K}$. Salinity retrievals using measured $T_{B}$ exhibit a 0.26 psu bias for the SSS from $0-37 \mathrm{psu}$, and SST from $14{ }^{\circ} \mathrm{C}$ to $20^{\circ} \mathrm{C}$. 
a)

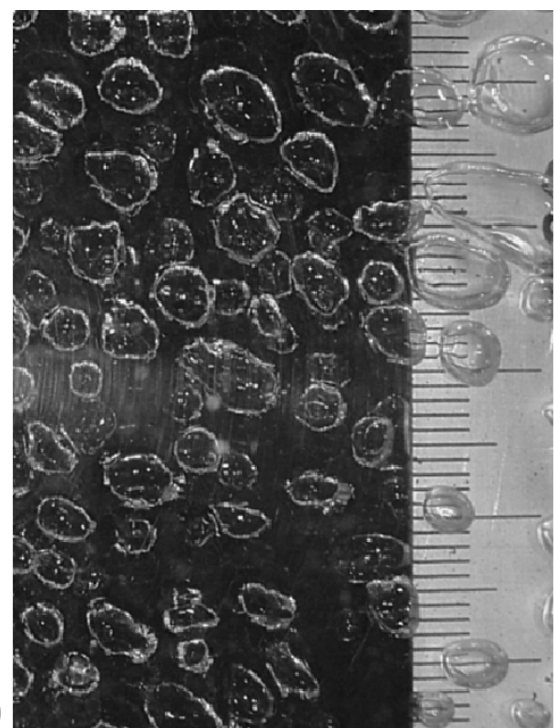

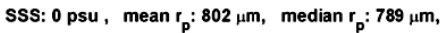

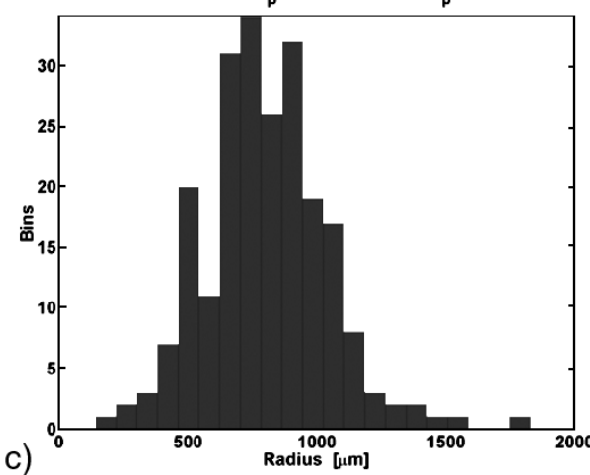

b)

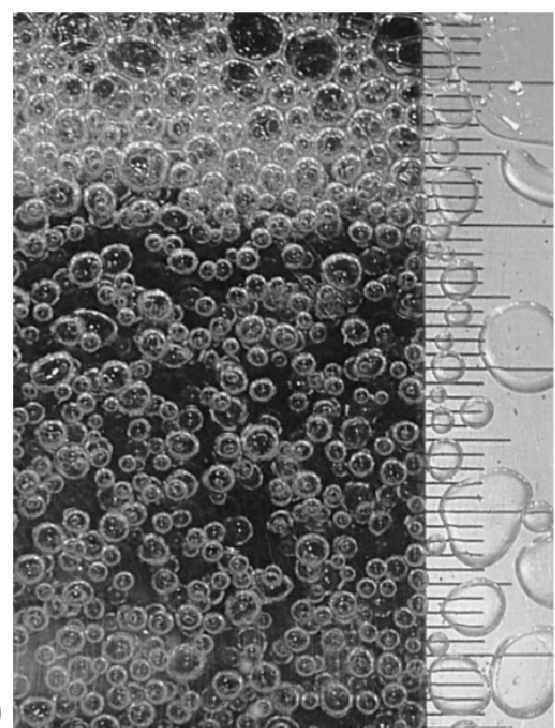

SSS: 15 psu, mean $r_{p}: 437 \mu \mathrm{m}$, median $r_{p}: 423 \mu \mathrm{m}$,

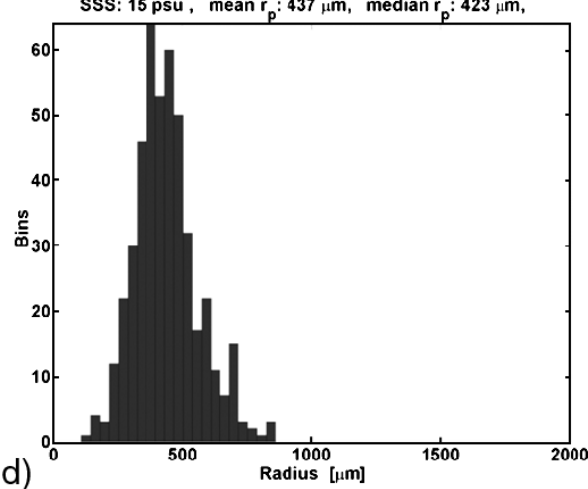

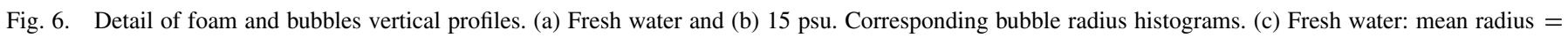
$802 \mu \mathrm{m}$, median radius $=789 \mu \mathrm{m}$ and (d) $15 \mathrm{psu}$ (mean radius $=437 \mu \mathrm{m}$, median radius $=423 \mu \mathrm{m}$ )

Foam Measurements: As explained in Section II, in addition to the foam surface coverage needed to estimate the foam emissivity from the measurements, modeling foam emission requires the knowledge of: 1) the foam layer thickness; 2) the bubbles' radii distribution; 3) the bubbles' water coating thickness; 4) the stickiness parameter; and 5) the air fraction beneath the foam layer, as follows.

- The foam layer thickness was measured by the video camera mounted on the periscope. For the same air flow rate the foam thickness is very small for fresh water (lower surface tension) and increases with increasing salinity (higher surface tension). Fig. 5 presents nine vertical profiles corresponding to nine different salinities from 0-37 psu. Automated image processing was used to determine the mean thickness of each photogram in a systematic manner.

- The estimation of the bubbles' radii distribution required the recognition of isolated bubbles, and finding the equivalent spherical bubble. Fresh water bubbles are larger, and their shape is less spherical than salty water bubbles. The measured mean radii are: $\sim 0.80 \mathrm{~mm}$ for fresh water bubbles [Fig. 6(a) and 6(c)], $\sim 0.63 \mathrm{~mm}$ at $5 \mathrm{psu}$, and nearly constant and approximately equal to $\sim 0.44 \mathrm{~mm}$ above 10 psu [Fig. 6(b) and 6(d)].
In order to check the goodness of the artificially generated foam as compared to natural foam encountered over the sea after a wave splash, 80 photographs of the sea surface (SSS $\sim 33.8 \mathrm{psu}$ ) were acquired in the coasts of the Gran Canaria island after wave breaking. A top view is shown Fig. 7(a), with its corresponding histogram [Fig. 7(b)]. This is representative of the whole volume, since the foam contained only one layer of bubbles. ${ }^{2}$ The most noticeable features of the histogram are that the average radius is $\sim 0.60 \mathrm{~mm}$, as compared to $\sim 0.40 \mathrm{~mm}$ for the artificially generated bubbles (Fig. 6), and that the histogram is less symmetric around the mean value, with a much longer tail, which corresponds to larger bubbles formed from combinations of smaller ones. The best fit by a gamma function bubble radii pdf is also shown in Fig. 7(c), showing that the measured histogram is more peaky and narrower than the gamma pdf.

- Bubbles' coating thickness measured from zooms of the vertical profiles (e.g., Figs. 6 and 7) are in the 10-20- $\mu \mathrm{m}$ range. However, this is not a critical parameter, since the foam emissivity, as predicted by the theoretical model explain in Section II, shows little variation with it.

${ }^{2}$ Other experiments [10] have shown the agreement between the bubble size histogram of artificially generated sea foam and natural sea foam. 

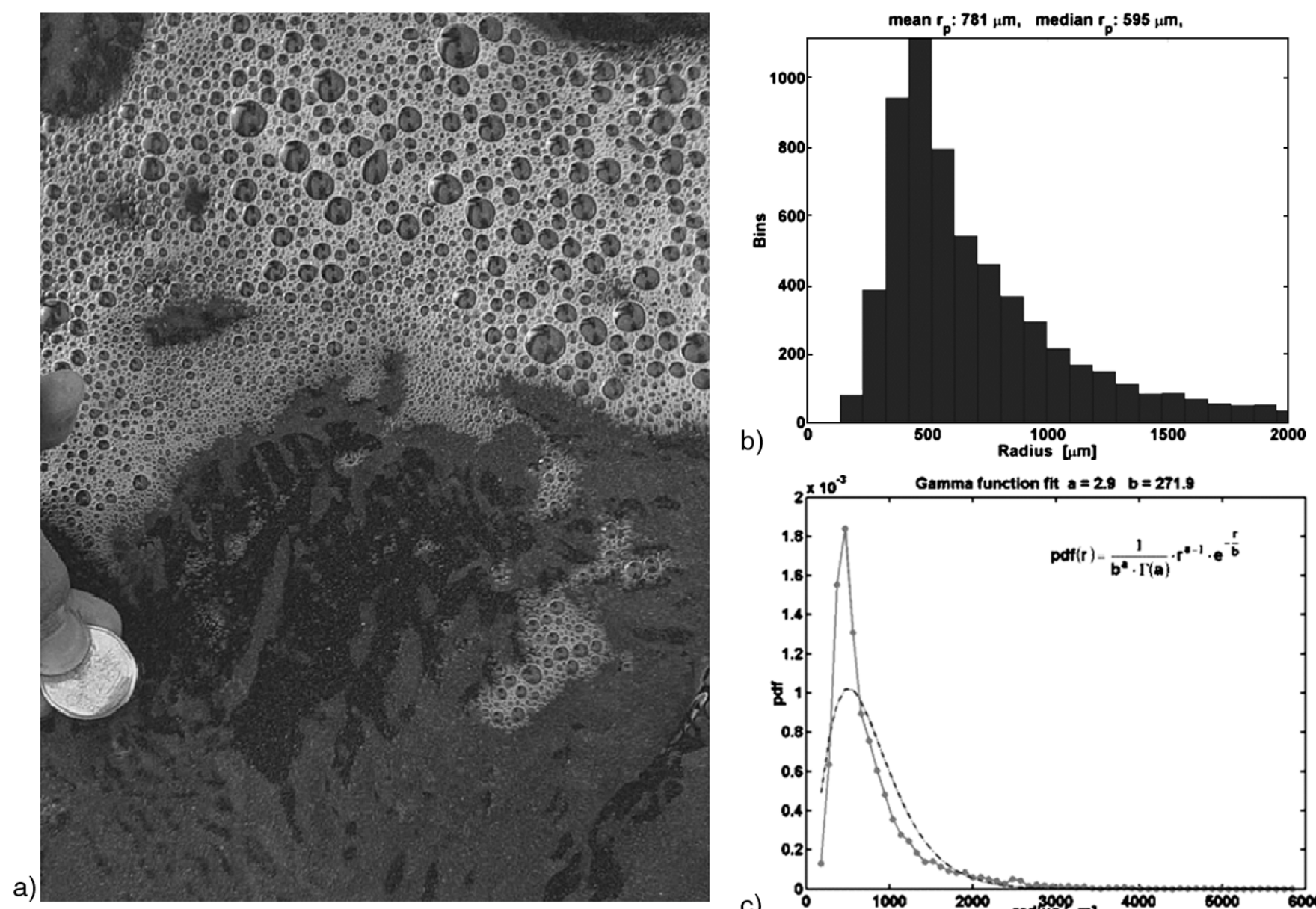

b)

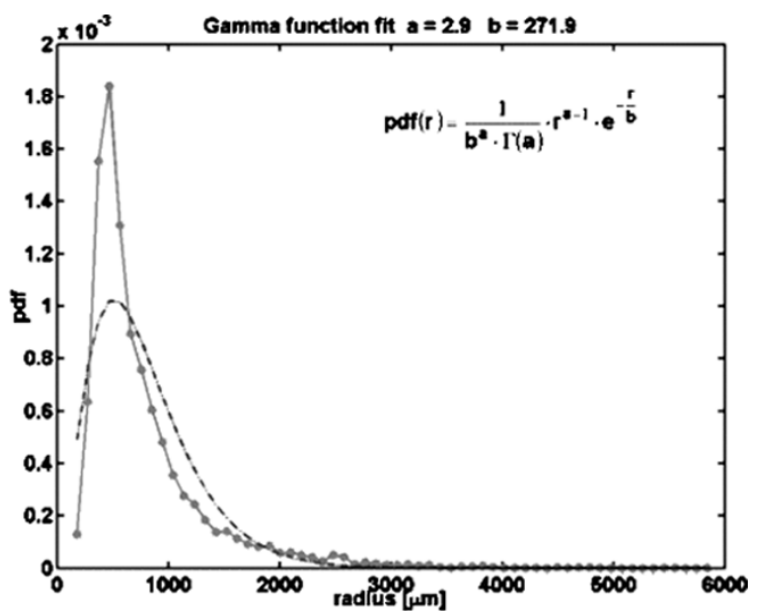

Fig. 7. (a) Top view of natural sea foam (Gran Canaria Island, scale: 50 euro cent coin). (b) Bubble radius histogram (mean radius $=781 \mu \mathrm{m}$, most probable radius $=595 \mu \mathrm{m}$. (c) Corresponding bubble radius histogram (higher peak function), and best fit by a gamma function (lower peak).

TABLE I

Estimated PACKING CoEFficient $\kappa$, MinimizING THE RMS ERROR BETWEEN THE FROG 2003 MEASUREMENTS AND THE THEORETICAL MODEL

\begin{tabular}{llll}
\hline SSS & Optimum $\kappa(H-p o l)$ & Optimum $\kappa(\mathrm{V}$-pol) & $\begin{array}{l}\text { Average } \kappa \\
\text { of H-and V-pol }\end{array}$ \\
\hline 5 & 0.14 & 0.03 & 0.08 \\
10 & 0.10 & 0.04 & 0.07 \\
15 & 0.13 & 0.11 & 0.12 \\
20 & 0.13 & 0.12 & 0.12 \\
25 & 0.17 & 0.15 & 0.16 \\
30 & 0.17 & 0.15 & 0.16 \\
34 & 0.21 & 0.17 & 0.19 \\
\hline
\end{tabular}

- The bubbles' packing coefficient or stickiness parameter plays a very important role in the foam emission. However, since no direct means has been found to measure it, the approach followed has been its determination by minimizing the rms error between the model and the measurements. Table I shows the different values of $\kappa$ found for different salinities and polarizations. Above 10 psu the values at both polarizations are very close, as expected, but for low salinities they are significantly different, which is not understood, although it may be attributed to the more flattened shape that the large bubbles have at low salinities, as compared to high salinities. In the third column the optimum $\kappa$ values are chosen to minimize the overall $\mathrm{rms}$ error at both polarizations.

- The void fraction beneath the foam layer is also a critical parameter. Its determination from video imagery is subject to large uncertainties due to the depth of the field of view $(\sim 1 \mathrm{~cm})$. To avoid this problem, the relative conductivity between foam and the air-water mixture below and water was measured. Curtayne's equation [14]

$$
\frac{\sigma_{\text {Foam }}}{\sigma_{\text {Water }}}=\frac{1}{3}\left(\phi_{l}+\phi_{l}^{1.5}+\phi_{l}^{2}\right)
$$

relates the ratio of the foam and water conductivities to the liquid fraction $\phi_{l}$. The void fraction beneath the foam layer $f_{a}$ can then be determined as

$$
f_{a}=100 \cdot\left(1-\phi_{l}\right)
$$

Fig. 8 shows two time series of the evolution of $f_{a}$ for each of the 16 gold electrodes. Fig. 9 shows the corresponding average and standard deviations of $f_{a}$ of each electrode. From these plots, derived from measurements acquired with the same air flow, it can be appreciated that for fresh water $f_{a}$ is $\sim 15 \%$ to 

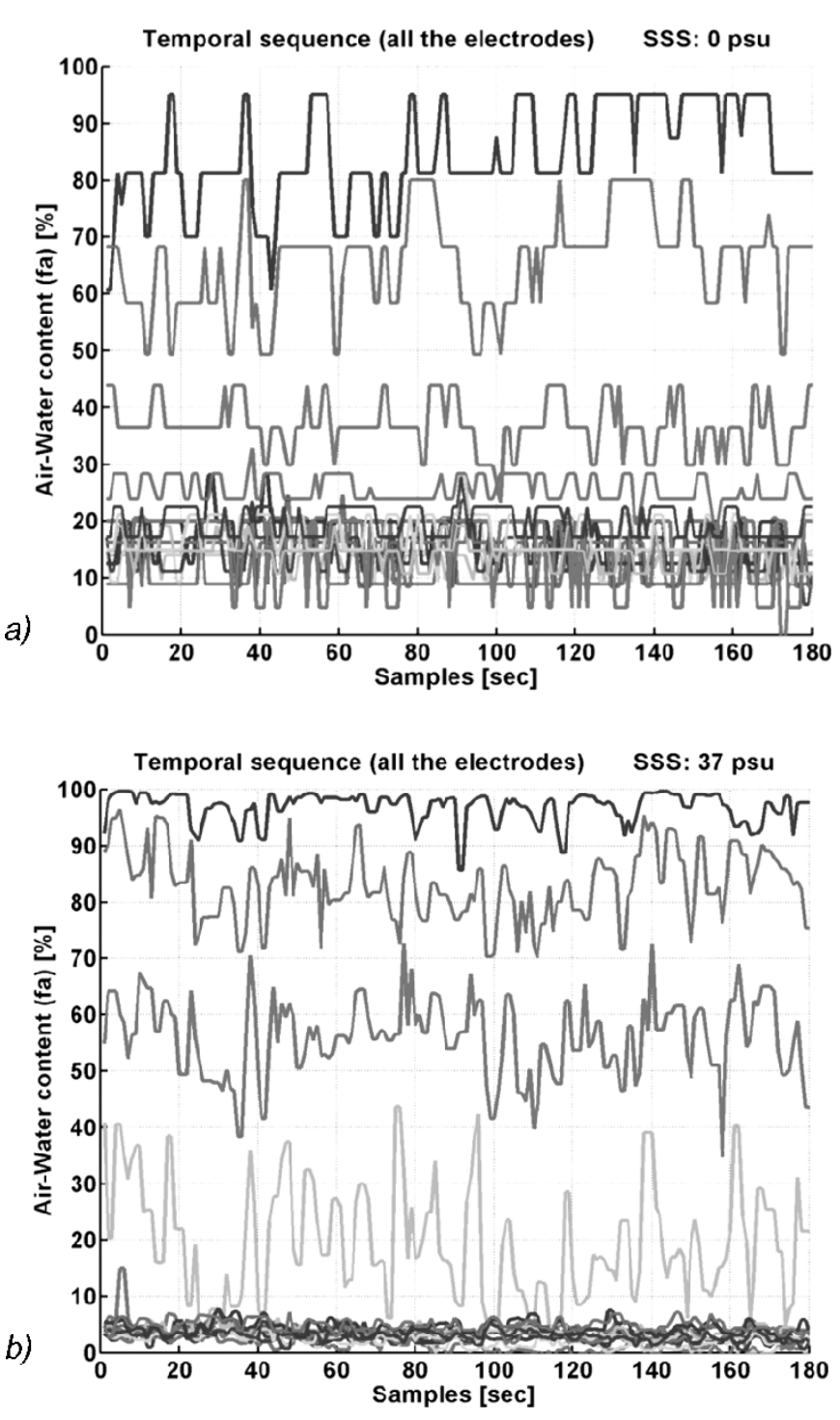

Fig. 8. Air-water content $\left(\mathrm{f}_{\mathrm{a}}\right)$ time sequence for every electrode. (a) SSS $=$ 0 psu (15 electrodes, the top electrode was air) and b) SSS $=37$ psu (16 electrodes).

$20 \%$ beneath the foam layer, increasing sharply just below the water surface, while for salty water, $f_{a}$ is much lower, $\sim 5 \%$, and the foam layer is thicker.

Fig. 10 shows a typical foam emissivity measurement corresponding to a salinity of $33.21 \mathrm{psu}$. Radiometers' raw data $(\mathrm{mV})$ are shown at $\mathrm{H}$ - (lower plot) and $\mathrm{V}$ - (upper plot) polarizations, and incidence angle (from $25^{\circ}$ to $55^{\circ}$, lower panel) as a function of the time [Fig. 10(a)]. The L-band surface emissivity is plotted at $\mathrm{H}$ - (lower plots) and $\mathrm{V}$ - (upper plots) polarizations of the foam-free surface (dotted line) and with foam (solid line). The foam coverage as a function of the incidence angle is shown in green in Fig. 10(b). The average foam coverage for all incidence angles is $86.4 \%$.

The foam emissivity can be derived from (16)

$$
e_{\mathrm{h}, \mathrm{v}}^{\text {Total }}(\theta)=F \cdot e_{\mathrm{h}, \mathrm{v}}^{\text {Foam }}(\theta)+[1-F] \cdot e_{\mathrm{h}, \mathrm{v}}^{\text {Water }}(\theta)
$$

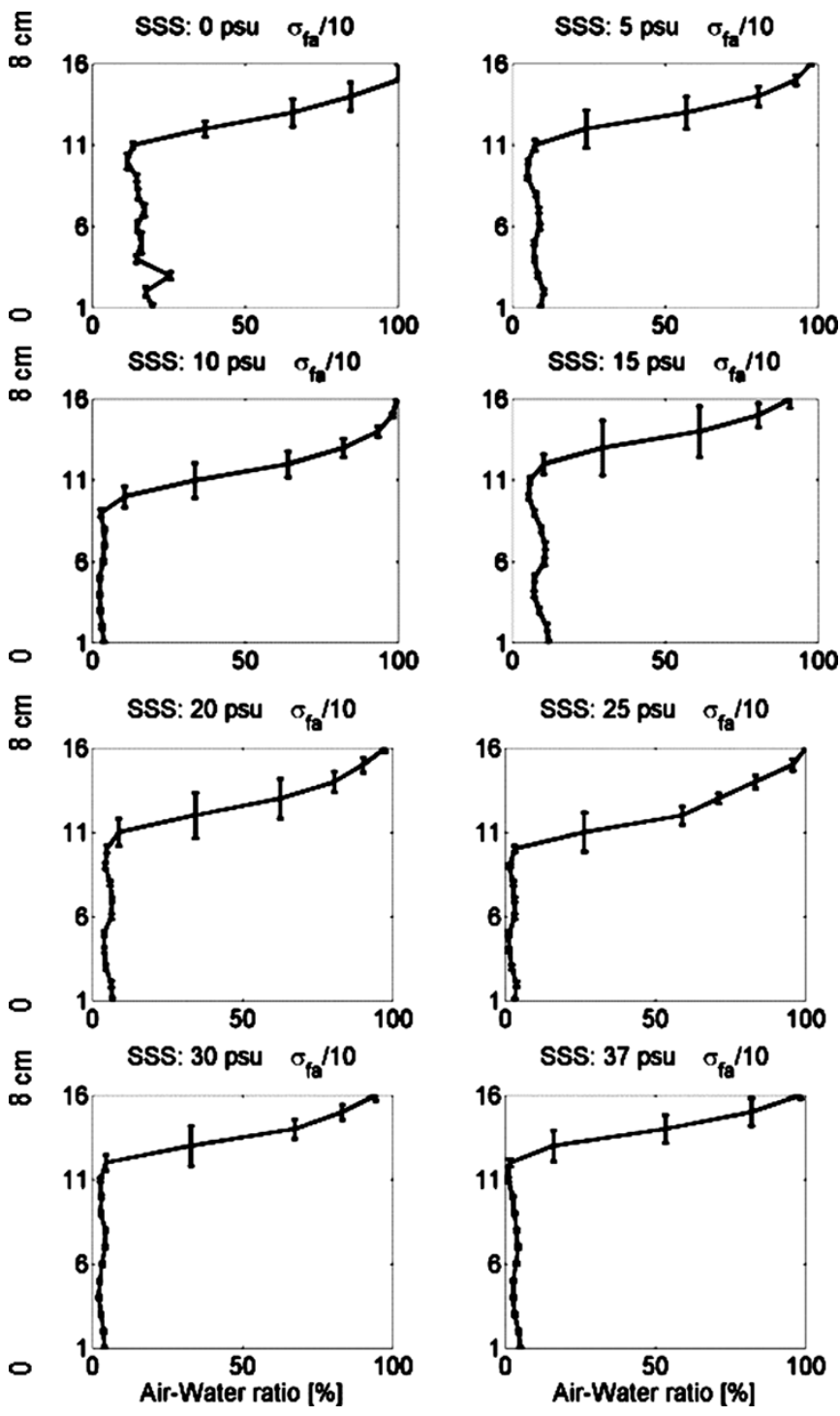

Fig. 9. Air-water fraction $\left(f_{a}\right)$ mean value and standard deviation of instantaneous values $\left(\sigma_{f a}\right.$ divided by 10) for every electrode at SSS $=0$ to 37 psu. Each parallel gold electrode ( $3 \mathrm{~mm} \times 4 \mathrm{~mm}$, total 16 electrodes) is separated by $2 \mathrm{~mm}$ from the adjacent electrode (vertical scale equals $8 \mathrm{~cm}$ ). Element number 16 is located above the surface, and hence the air-water ratio is $100 \%$.

where $F$ is the foam fraction coverage (in the sea it is determined by the wind, the air-sea instability, the fetch, the salinity etc., [15]) from which the variation with respect to the flat surface can be derived

$$
\Delta e_{\mathrm{h}, \mathrm{v}}(\theta)=e_{\mathrm{h}, \mathrm{v}}^{\text {Foam }}(\theta)-e_{\mathrm{h}, \mathrm{v}}^{\text {Water }}(\theta)=\frac{e_{\mathrm{h}, \mathrm{v}}^{\text {Total }}(\theta)-e_{\mathrm{h}, \mathrm{v}}^{\text {Water }}(\theta)}{F} .
$$

Fig. 11(a)-(h) shows the intercomparison of the FROG measurements of $e^{\text {Water }}$ (dotted line) and $e^{\text {Foam }}$ (solid lines with circles) scaled to $100 \%$ coverage (16), and the theoretical values computed using the model described in Section II with the measured foam parameters as inputs (solid lines with triangles). The values of the stickiness parameter used are the 

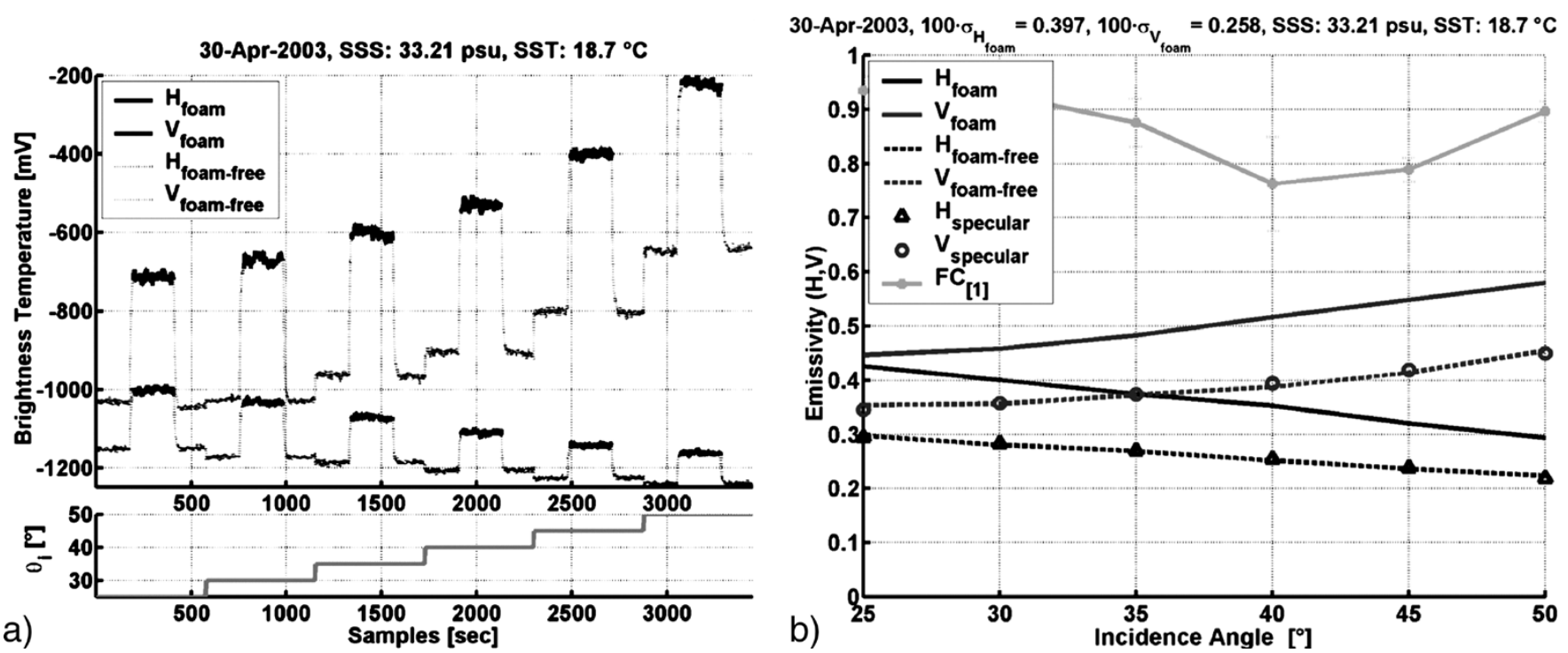

Fig. 10. Foam emissivity measurement at 33.21 psu. (Lower curves) H-polarization and (upper curves) V-polarization, with (solid line) foam and (dotted line) without foam. (a) Radiometers' raw data (millivolts) versus (lower plot) incidence angle and (b) surface's emissivity and (light gray plot) foam coverage as a function of incidence angle. The variation of the surface's foam coverage versus incidence angle is due to the variation of the foam patterns generated by the array of diffusers in the $3 \mathrm{~m} \times 7 \mathrm{~m}$ pool [see Fig. 4(h)].

optimum ones found at each salinity, which in general increases with SSS as the bubbles are more densely packed, as shown in Table I. The rms error between the measured data and the theoretical foam emissivity model is calculated and shown in each figure $\left(\sigma_{\Delta \mathrm{h}, \mathrm{v}}\right)$ and varies from 0.008 to 0.017 at $\mathrm{H}$-polarization, and from 0.011 to 0.033 at $\mathrm{V}$-polarization. In general the agreement is much better at $\mathrm{H}$-polarization than at $\mathrm{V}$-polarization. At V-polarization, the measured values show a larger variation with incidence angle than the model predictions, which requires further analysis and refinement of the model. At H-polarization the agreement is excellent, except at low salinities, where there is a bias between the measured and predicted emissivites at all incidence angles.

As shown by Guo et al. [5, Figs. 6-8], the presence of foam increases the brightness temperature (emissivity) almost linearly with foam thickness until it saturates. ${ }^{3}$ Finally, Fig. 12 shows the measured $\Delta e_{\mathrm{h}, \mathrm{v}}(\theta)$ values normalized to the foam thickness as a function of the salinity at $\mathrm{H}$ - and $\mathrm{V}$-polarizations. The oscillations in Figs. 12(a) and 12(b) at low salinity levels are due to the small values of the foam thickness, which are difficult to measure [e.g., Fig. 5(a)]. Fig. 12(c) and (d) shows the smoothed values.

As found during the WISE measurements [16], at L-band the foam emissivity increase is larger at $\mathrm{V}$-polarization than at $\mathrm{H}$-polarization, and it increases with incidence angle at $\mathrm{V}$-polarization, while it decreases at $\mathrm{H}$-polarization. In order to get the same foam brightness temperature increase as in WISE [16], the effective foam thickness (assumed to be the same for all foam patches regardless of the type of foam) should be approximately $8 \mathrm{~mm}$.

${ }^{3}$ Brightness temperature saturation depends on bubble size and frequency. At $37 \mathrm{GHz}$ it takes place for foam thickness around $4-8 \mathrm{~cm}$, and at $19 \mathrm{GHz}$ around 16-22 cm [5, Fig. 6]. No numerical simulations have been reported at L-band, but the saturation thickness must be much larger. Indeed, in the FROG 2003 measurements, the emissivity increase is very modest, which suggests that the thickness of the generated foam is far away from the saturation thickness.

\section{CONCLUSION}

The presence of foam increases the emitted brightness temperature, since it acts as a transition layer that adapts the wave impedance of the two media: water and air. The increase depends on the fraction of the sea surface covered by foam $F\left(U_{10}\right)$, which is usually parameterized in terms of the wind speed, but it depends on other factors, such as the air-sea temperature difference, the sea surface temperature, the fetch, etc. [15]

$$
\begin{aligned}
e_{p}^{\text {Total }}(\theta) & =F\left(U_{10}\right) \cdot e_{p}^{\text {Foam }}+\left[1-F\left(U_{10}\right)\right] \cdot e_{p}^{\text {Sea }} \\
& =e_{p}^{\text {Sea }}+F\left(U_{10}\right) \cdot\left[e_{p}^{\text {Foam }}-e_{p}^{\text {Sea }}\right] \\
& =e_{p}^{\text {Sea }}+F\left(U_{10}\right) \cdot \Delta e_{p}^{\text {Foam }} .
\end{aligned}
$$

The FROG 2003 experiment has provided the first reported L-band emissivity measurements of artificially generated foam on a salt sea water surface over a wide range of incidence angles and salinities at both polarizations. The ancillary data acquired (foam thickness, air-water fraction, bubble size distribution and water coat thickness) have been used as inputs of a simple two-layer theoretical model. The intercomparison of model outputs with the measured emissivities has allowed the retrieval of the packing coefficient, which is approximately $\kappa=$ 0.112 for all salinities, and $\kappa=0.19$ at $S S S=34$ psu. At V-pol the model and the measurements tend to disagree at higher salinities, and at H-pol at lower salinities. From 6-34 psu, the agreement is very good. In addition, the contribution of errors in the estimation of the foam emissivity to the error of the sea surface emission are attenuated by a factor equal to the sea surface foam coverage ( $\sim 1 \%$ at $15 \mathrm{~m} / \mathrm{s})$. The results obtained in FROG 2003 , and the foam emissivity and coverage derived from WISE 2001 measurements, indicate that an effective foam thickness of $\sim 8 \mathrm{~mm}$ may be appropriate to model in a simple way the foam contribution to sea surface emission. 
a)

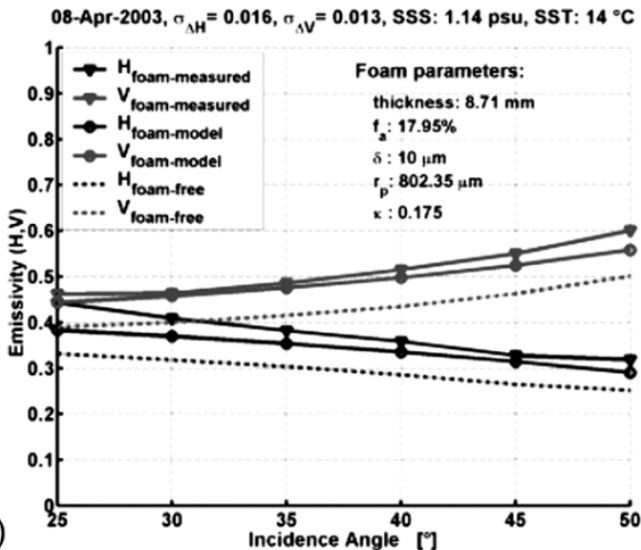

27-Apr-2003, $\sigma_{S H}=0.009, \sigma_{A V}=0.011$, SSS: 10.49 psu, SST: $20.6{ }^{\circ} \mathrm{C}$

c)

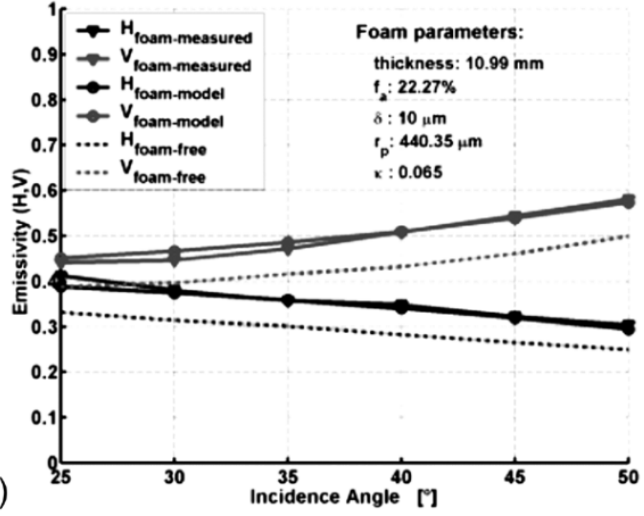

28-Apr-2003, $\sigma_{A \mathrm{H}}=0.009, \sigma_{A V}=0.024$, SSS: 23.24 psu, SST: $20^{\circ} \mathrm{C}$

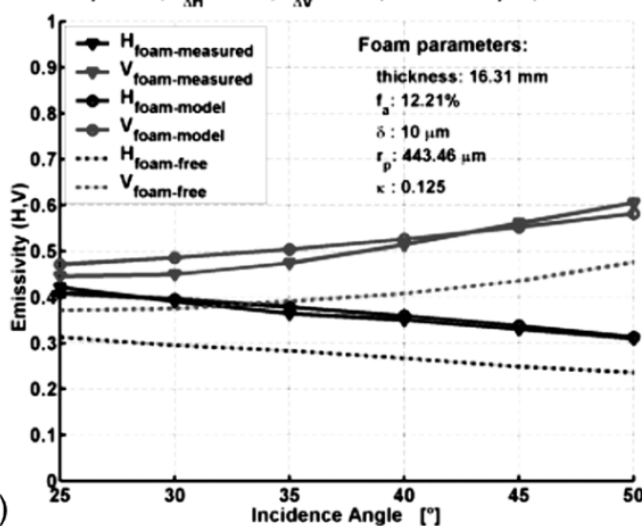

e)

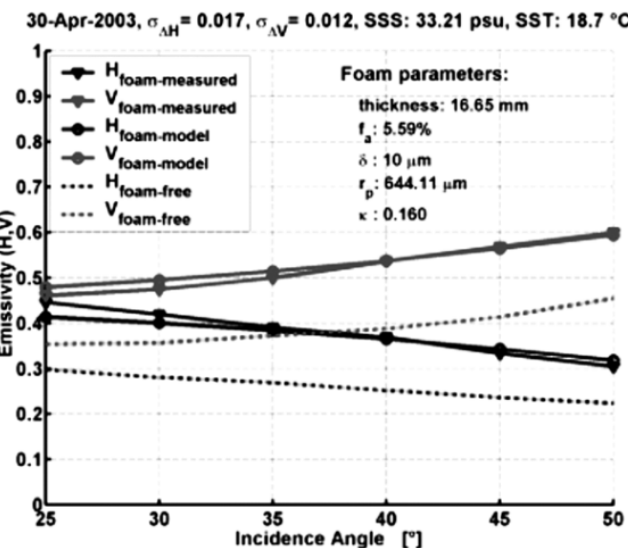

26-Apr-2003, $\sigma_{\mathrm{AH}}=0.011, \sigma_{\mathrm{AV}}=0.011$, SSS: $6.18 \mathrm{psu}, \mathrm{SST}: 19^{\circ} \mathrm{C}$

b)

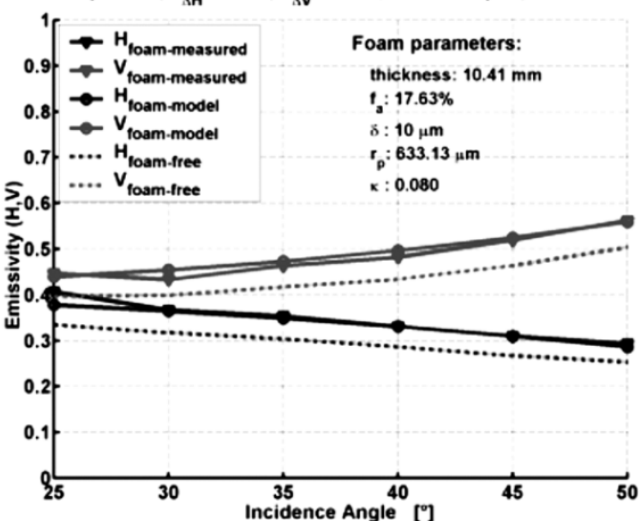

25-Apr-2003, $\sigma_{A H}=0.010, \sigma_{A V}=0.018$, SSS: 16.29 psu, SST: $18.4^{\circ} \mathrm{C}$

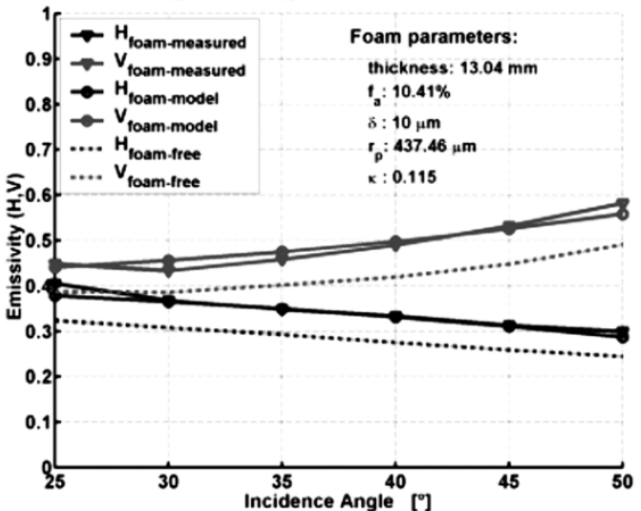

24-Apr-2003, $\sigma_{A H}=0.008, \sigma_{A V}=0.032$, SSS: 25.5 psu, SST: $18.8^{\circ} \mathrm{C}$

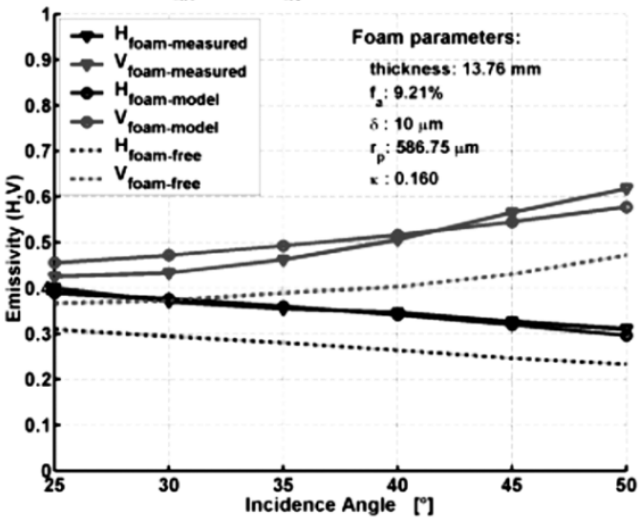

23-Apr-2003, $\sigma_{A H}=0.011, \sigma_{A V}=0.033$, SSS: 37.33 psu, SST: $15.6{ }^{\circ} \mathrm{C}$

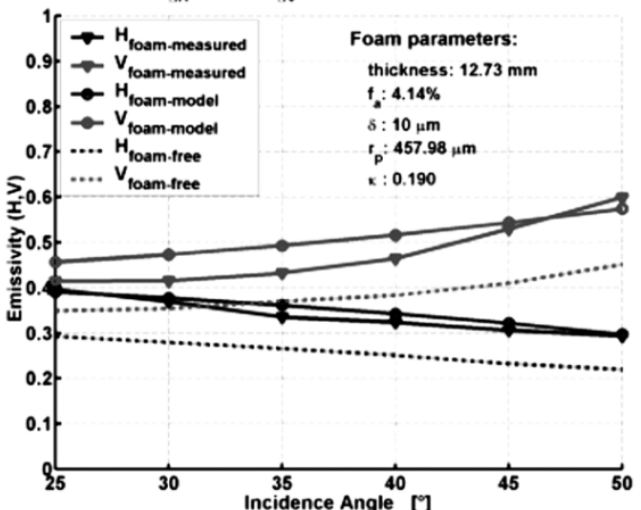

Fig. 11. Emissivities at (lower three plots in each panel) H-polarization and (upper three plots in each panel) V-polarization for different salinities in the 1-37-psu range. Dashed lines indicate foam-free conditions. (Solid line with circles) FROG measurements. (Solid line marked with triangles) Theoretical model with measured parameters: foam thickness, bubbles radii, air-water fraction, $\delta=10 \mu \mathrm{m}$, and optimum packing coefficient derived by fitting the emission model to the measurements. 


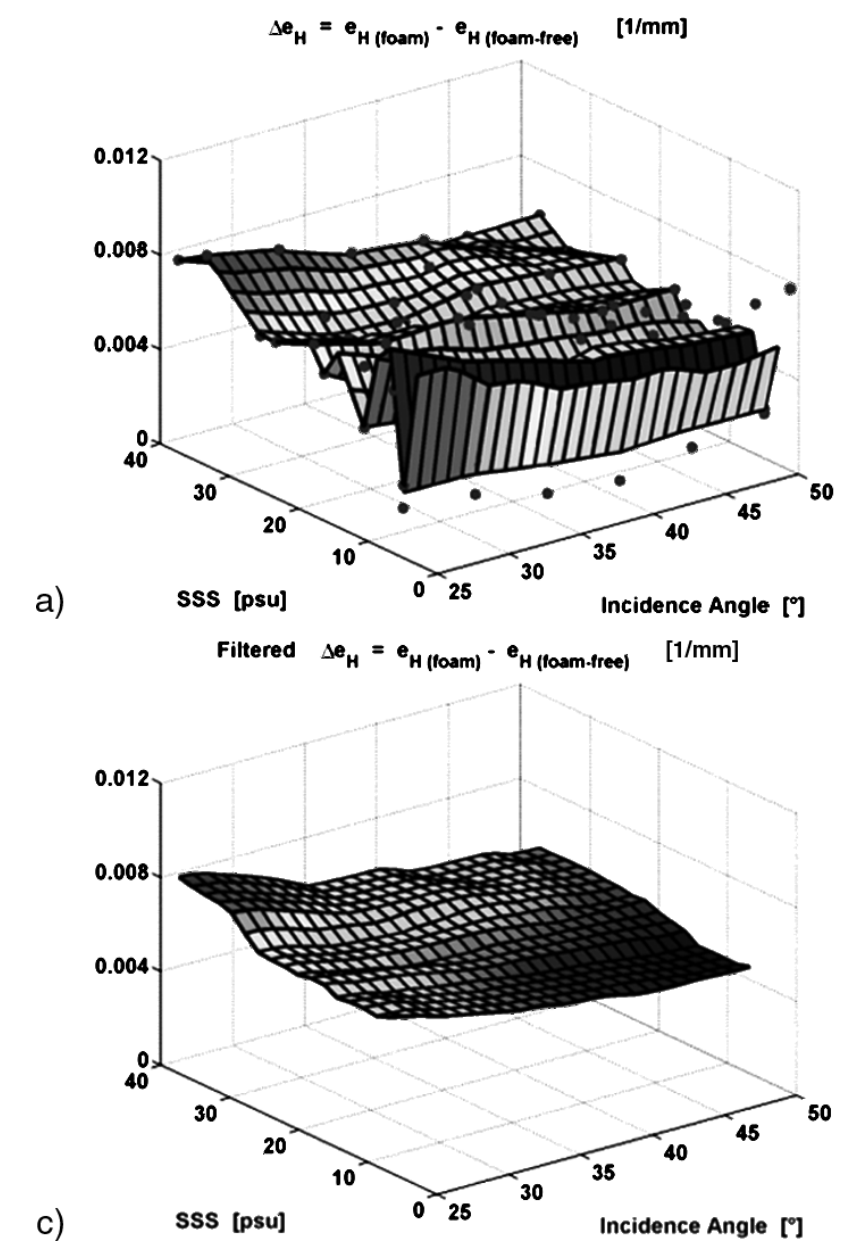

b)

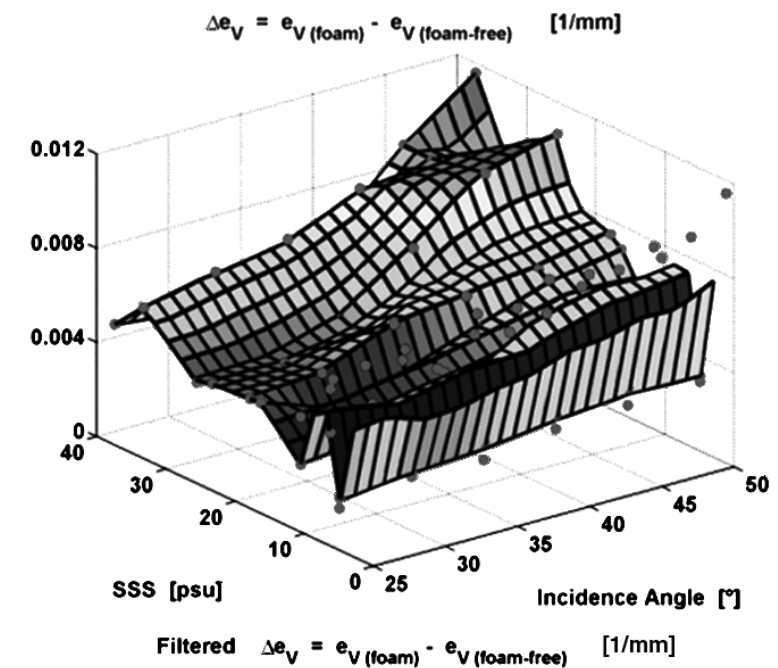

d)

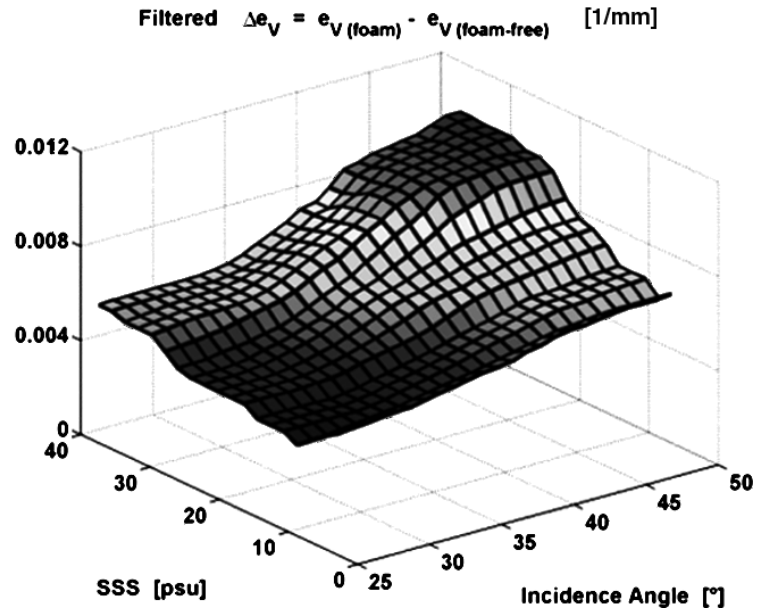

Fig. 12. Foam emissivity increase per foam thickness unit in millimeters, at $100 \%$ coverage, at $\mathrm{H}$ - and V-polarizations as a function of SSS and $\theta_{i}$. (a) Measured data points (H-polarization). (b) Measured data points (V-polarization). (c) Panel (a) low-pass filtered. (d) Panel (b) low-pass filtered. Oscillations in (a) and (b) are due to errors in the foam thickness measurement, which is very small for low salinities.

\section{ACKNOWLEDGMENT}

Special thanks are given to the Institut de Recerca de Tècniques Agropequàries (IRTA)-Poble Nou del Delta personnel for their help during the experiment at their facilities and to J. Font, C. Gabarró, and A. Julià (Institut de Ciències del Mar CMIMA/CSIC-Barcelona) for analyzing the water samples. The authors wish to acknowledge two anonymous reviewers for their comments to improve the clarity of the text.

\section{REFERENCES}

[1] G. S. E. Lagerloef. (2000, Jan.) Report of the Third Workshop, Salinity Sea Ice Working Group, Field Programs and Algorithms: Satellites and Science, San Antonio, Texas, USA. [Online]. Available: http://www.esr.org/ssiwg3/SSIWG_3.html

[2] J. Johannessen et al., "Scientific requirements and impact of space observations of ocean salinity for modeling and climate studies," ESA, Noordwijk, The Netherlands, Final Report, ESA Contract 14273/00/NL/DC, 2002

[3] C. T. Swift and R. E. McIntosh, "Considerations for microwave remote sensing of ocean-surface salinity," IEEE Trans. Geosci. Electron., vol. GE-21, no. 4, pp. 480-491, Oct. 1983.
[4] A. Camps, J. Font, M. Vall-llossera, C. Gabarró, I. Corbella, N. Duffo, F. Torres, S. Blanch, A. Aguasca, R. Villarino, L. Enrique, J. Miranda, J. Arenas, A. Julià, J. Etcheto, V. Caselles, A. Weill, J. Boutin, S. Contardo, R. Niclós, R. Rivas, S. C. Reising, P. Wursteisen, M. Berger, and M. Martin-Niera, "The WISE 2000 and 2001 campaigns in support of the SMOS mission: Sea surface L-band brightness temperature observations and their application to multiangular salinity retrieval," IEEE Trans. Geosci. Remote Sens., vol. 42, no. 4, pp. 804-824, Apr. 2004.

[5] J. Guo, L. Tsang, W. Asher, K.-H. Ding, and C.-T. Chen, "Applications of dense media radiative transfer theory for passive microwave remote sensing of foam covered ocean," IEEE Trans. Geosci. Remote Sens., vol. 39, no. 5, pp. 1019-1027, May 2001.

[6] L. A. Dombrovskiy and V. Y. Raizer, "Microwave model of a two-phase medium at the ocean surface," Izvestiya, Atmos. Oceanic Phys., vol. 28, no. 8, pp. 650-656, 1992

[7] V. Cherny and V. Y. Raizer, Passive Microwave Remote Sensing of Oceans. New York: Wiley, 1998.

[8] L. M. Zurk, L. Tsang, K. H. Ding, and D. P. Winebrenner, "Monte Carlo simulations of the extinction rate of densely packed spheres with clustered and nonclustered geometries," J. Opt. Soc. Amer, vol. 12, pp. 1772-1781, Aug. 1995.

[9] L. A. Dombrovskiy, "Calculation of the thermal radiation emission of foam on the sea surfacew," Izvestiya, Atmos. Oceanic Phys., vol. 15, no. 3, pp. 193-198, 1979.

[10] R. D. Peltzer and O. M. Griffin, "Stability and decay properties of foam in seawater,", NRL Memo. Rep. 5949, Apr. 24, 1987.

[11] J. Wu, "Variation of whitecap coverage with wind stress and water temperature," J. Phys. Oceanogr., vol. 18, pp. 1448-1453, 1988. 
[12] G. S. Bordonskiy, I. B. Vasil'kova, N. N. V. V. M. Veselov, Y. A. Militskiy, V. G. Mirovskiy, V. N. Nkitin, V. Y. Raizer, Y. B. Khapin, Y. A. Sharkov, and V. S. Etkin, "Spectral characteristics of the emissivity of foam formations," Izvestiya, Atmos. Oceanic Phys., vol. 14, no. 6, pp. 464-469, 1978.

[13] L. A. Klein and C. T. Swift, "An improved model for the dielectric constant of sea water at microwave frequencies," IEEE J. Oceanic Eng., vol. OE-2, no. 1, pp. 104-111, 1977.

[14] D. Weaire and S. Hutzler, The Physics of Foams. Oxford: Clarendon, 1999.

[15] E. C. Monahan and M. Lu, "Acoustically relevant bubble assemblages and their dependence on metereological parameters," IEEE J. Oceanic Eng., vol. 15, pp. 340-349, Oct. 1990.

[16] R. Villarino, A. Camps, M. Vall-llossera, J. Miranda, and J. Arenas, "Sea foam and sea state effects on the instantaneous brightness temperatures at L-band," in Proc. 1st Results Workshop on WISE/LOSAC/EuroSTARSS Campaigns, Nov 4-6, 2002, pp. 95-103.

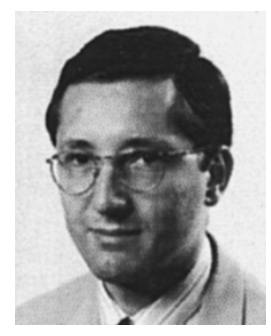

Adriano Camps (S'91-A'97-M'00-SM'02) was born in Barcelona, Spain, in 1969. He received the Telecommunications Engineering degree and the $\mathrm{Ph} . \mathrm{D}$. degree in telecommunications engineering in 1992 and 1996, respectively, both from the Polytechnic University of Catalonia (UPC), Barcelona, Spain.

From 1991 to 1992 , he was with the ENS des Télécommunications de Bretagne, Bretagne, France, with an Erasmus Fellowship. In 1993, he joined the Electromagnetics and Photonics Engineering group, at the Department of Signal Theory and Communications, UPC, as an Assistant Professor, and since 1997 as an Associate Professor. In 1999, he was on sabbatical leave at the Microwave Remote Sensing Laboratory, University of Massachusetts, Amherst. His research interests are microwave remote sensing, with special emphasis in microwave radiometry by aperture synthesis techniques. He has performed numerous studies within the frame of European Space Agency SMOS Earth Explorer Mission. He is an Associate Editor of Radio Science.

Dr. Camps received the second national award of university studies in 1993, the INDRA award of the Spanish Association of Telecommunication Engineering to the best Ph.D. in 1997, the extraordinary Ph.D. award at the Universitat Politècnica de Catalunya in 1999, the First Duran Farell Award and the Ciudad de Barcelona Award, in 2000 and 2001, respectively, both for Technology Transfer, in 2002, the Research Distinction of the Generalitat de Catalunya for contributions to microwave passive remote sensing, in 2003, the Premi Nacional de Telecomunicacions (Generalitat de Catalunya) with the members of the Electromagnetics and Photonics Engineering group, and in 2004 a EURYI (European Young Investigator) Award. Also, as a member of the Microwave Radiometry Group at UPC, he received in 2000, 2001, and 2004 the 1st Duran Farell and the Ciudad de Barcelona Awards for Technology Transfeer, and the Salvà i Campillo Award of the Telecommunications (Engineering College of Catalonia) to the most innovative research project. He was Chair of Cal '01. He is editor of the IEEE Geoscience and Remote Sensing Newsletter and President-Founder of the IEEE Geoscience and Remote Sensing Society Spain Chapter.

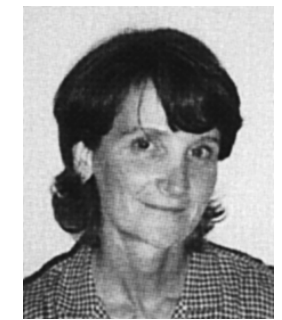

Mercè Vall-llossera (M'99) received the Senior Telecommunication Engineer and the Doctor Telecommunication Engineering degrees in 1990 and 1994, respectively, both from the Polytechnic University of Catalonia (UPC), Barcelona, Spain.

She has been lecturing and doing research at the Department of Signal Theory and Communications, UPC from 1990 until 1997 as an Assistant Professor and from 1997 until present as an Associate Professor. She spent a sabbatical year in Montreal with the scholarship of the "Programme Québécois de Bourses d'excellence" (1996-1997): "Stages de Formation postdoctorale au Québec pour jeunes diplômés étrangers.” Her research interests include numerical methods in electromagnetism, microwave radiometry, antenna analysis, and design. Currently, her research is mainly related to the study of numerical methods applied to the sea surface emissivity and their characterization at L-band and the MIRAS/SMOS project.

Dr. Vall-llossera, along with the other members of the radiometry group at UPC, was awarded the "9th Edition of the Salvà i Campillo Award" in 2004, the "Primer Premio Duran Farell de Investigación Tecnológica" in 2002, and the "Primer Premio Ciutat de Barcelona d'Investigació Tecnològica" in 2001.

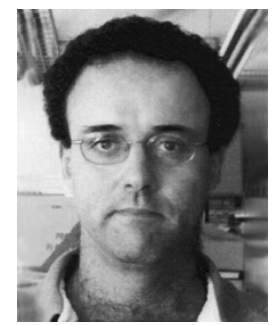

Ramón Villarino (S'04) received the Ingeniero and $\mathrm{Ph} . \mathrm{D}$. degrees in telecommunications from the Polytechnic University of Catalonia (UPC), Barcelona Spain, in 2000 and 2004, respectively.

He has participated in the development and construction of an L-band radiometer and in the two WISE field experiments sponsored by ESA during 2000-2002, in the FROG 2003 field experiment to determine the emissivity of foam at L-band, and in the MOUSE 2004 experiment carried out at JRC-Ispra to determine the emissivity of different types of soils.

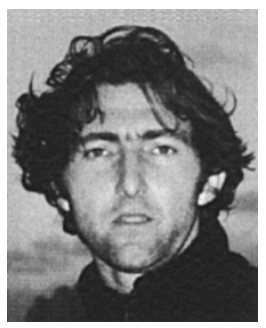

Nicolas Reul received the B.S. degree in marine sciences engineering from Toulon University, La Garde Cedex, France, and the Ph.D. degree in physics (fluid mechanics) from the University Aix-Marseille II, Marseille, France, in 1993 and 1998, respectively.

From 1999 to 2001, he was a Postdoctoral Researcher at the Applied Marine Physics Department, team of Prof. M. Donelan, Rosenstiel School of Marine and Atmospheric Science, University of Miami. Since 2001, he has been a Permanent Rsearcher at the Département Océanographie Spatiale, Institut Francais de Recherche et d'Exploitation de la Mer, responsible for the activities concerning the future SMOS satellite mission. The focus of his research program is to improve understanding of the physical processes at air-sea interface and passive/active remote sensing of the ocean surface. He has experience in applied mathematics, physical oceanography, electromagnetic wave theory, and its application to ocean remote sensing. He is presently a member of the ESA/SMOS Science Advisory Group. 


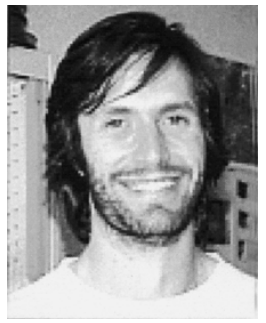

Bertrand Chapron received the B.Eng. degree from Institut National Polytechnique de Grenoble, Grenoble, France, and the Ph.D. degree in physics (fluid mechanics) from the University of Aix-Marseille II, Marseille, France, in 1984 and 1988, respectively.

He spent three years as a Postdoctoral Research Associate at the NASA Goddard Space Flight Center, Wallops Flight Facility. He has experience in applied mathematics, physical oceanography, electromagnetic wave theory, and its application to ocean remote sensing. He is currently a Research Scientist and is Head of the Spatial Oceanography group at the Institut Francais de Recherche et d'Exploitation de la Mer, Responsible of the Centre ERS Archivage et Traitement. He is a Collaborator or Principal Investigator in several ESA (ENVISAT, Global Navigation Satellite System), NASA, and CNES (TOPEX/POSEIDON, JASON) projects. He is Coresponsible (with H. Johnsen, NORUT) of the ENVISAT ASAR-wave mode algorithms and scientific preparation for the ENVISAT wind and wave products.

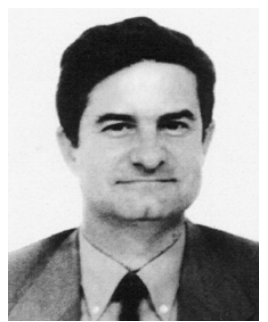

Ignasi Corbella (M'99) received the Telecommunications Engineering and Dr.Eng. degrees, both from Universitat Politècnica de Catalunya (UPC), Barcelona, Spain, in 1977 and 1983, respectively.

In 1976, he joined the School of Telecommunication Engineering in UPC as a Research Assistant in the Microwave Laboratory, where he worked on passive microwave integrated circuit design and characterization. During 1979, he worked at ThomsonCSF, Paris, France, on microwave oscillators design. In 1982, he became an Assistant Professor at UPC, an Associate Professor in 1986, and a Full Professor in 1993. He is currently teaching microwaves at the undergraduate level in UPC and has designed and taught graduate courses on nonlinear microwave circuits. During the school year 1998-1999, he worked at NOAA/Environmental Technology Laboratory, Boulder, $\mathrm{CO}$, as a Guest Researcher, developing methods for radiometer calibration and data analysis. His research work in the Department of Signal Theory and Communications, UPC includes microwave airborne and satellite radiometry and microwave system design.

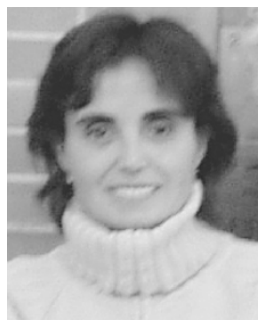

Núria Duffo (S'91-M'99) received the Telecommunication Engineer degree from the Polytechnic University of Catalonia (UPC), Barcelona, Spain, and the Doctor in Telecommunication Engineering from UPC, in 1990 and 1996, respectively.

Since 1997, she has been an Associate Professor at UPC. Her current research interests are numerical methods in electromagnetics, microwave radiometry, antenna analysis, and design.

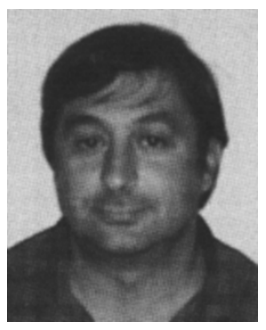

Francesc Torres (M'96) received the Ingeniero and Doctor Ingeniero degrees in telecommunication engineering from the Polytechnic University of Catalonia (UPC), Barcelona, Spain, in 1988 and 1992, respectively.

In 1988-1989, he was a Research Assistant in the RF System Division, European Space Agency, Noordwijk, The Netherlands, devoted to microwave device testing and characterization. In 1989, he joined the Antenna-Microwave-Radar group, UPC, where he is currently an Associate Professor. His main research interests are focused on the design and testing of microwave systems and subsystems. He is currently engaged in research on interferometric radiometers devoted to earth observation.

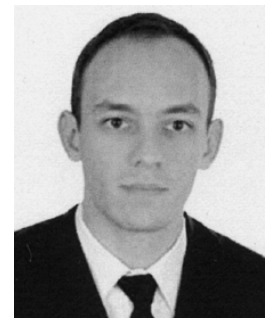

Jorge José Miranda (S'04) was born in Las Palmas de Gran Canaria, Canary Islands, Spain, in 1973. $\mathrm{He}$ received the Telecommunication Technical Engineering degree from Las Palmas de Gran Canaria University (ULPGC), Spain, and the Senior Telecommunication Engineering degree from the Polytechnic University of Catalonia (UPC), Barcelona, Spain, in 1996 and 2001, respectively. He is currently pursuing the Ph.D. degree in telecommunication engineering from UPC. His Ph.D. thesis is focused on the sea surface emissivity at L-band. It includes the development of new models for determining the sea surface roughness and the comparison and improvement of existing emissivity models.

From 1996 to 1999, he was with the Remote Sensing and Radar Laboratory (EUITT-ULPGC), where collaborated in satellite image processing. In 1999, he joined the Signal Theory and Communications Department, UPC. Since 2002, he has been an Assistant Professor at the UPC.

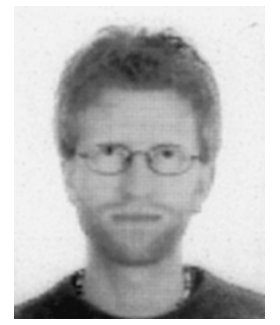

Roberto Sabia (S'03) was born in Naples, Italy, on November 13. 1975. He graduated (cum laude) in marine environmental sciences (five-year course study), curriculum in oceanography, from the Università degli Studi di Napoli "Parthenope," Naples, in 2002. He is is currently pursuing a Ph.D. degree in signal theory and communications at the Universitat Politécnica de Catalunya (UPC), Barcelona, Spain

In 2002, he was recipient of a grant from the Microwave Remote Sensing Laboratory, Università degli Studi di Napoli "Parthenope," on sea surface scattering models. In 2003, he joined the Department of Signal Theory and Communications, UPC. In 2003, he participated in FROG 2003 and REFLEX 2003 measurements campaigns. He is actually working on a research contract within the ESA's SMOS project. His main research interests deal with microwave radiometry and sea surface salinity retrieval.

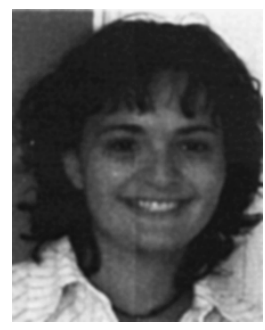

Alessandra Monerris (S'03) was born in Valencia, Spain, in 1977. She received the degree in telecommunication engineering from the Universitat Politècnica de València (UPV), Valencia, Spain, in 2001. She she is currently pursuing the Ph.D. degree at the Universitat Politècnica de Catalunya (UPC), Barcelona, Spain.

She was with the Group of Microwave Applications from UPV developing numerical methods for the electromagnetic analysis of waveguide-based devices. In 2002, she joined the Department of Signal Theory and Communications, UPC. Her main research interests deal with surface soil moisture retrieval algorithms from brightness temperature measurements.

Rubén Rodríguez, photograph and biography not available at the time of publication. 